\title{
Annexin1 regulates DC efferocytosis and cross-presentation during Mycobacterium tuberculosis infection
}

\author{
Fanny Tzelepis, ${ }^{1}$ Mark Verway, ${ }^{1}$ Jamal Daoud, ${ }^{2}$ Joshua Gillard, ${ }^{1}$ Kimya Hassani-Ardakani, ${ }^{1}$ Jonathan Dunn, ${ }^{1}$ Jeffrey Downey, ${ }^{1}$ \\ Marilena Elena Gentile, ${ }^{1}$ Joanna Jaworska, ${ }^{1}$ Anthony Michel Jean Sanchez, ${ }^{1}$ Yohann Nédélec, ${ }^{3}$ Hojatollah Vali, ${ }^{4}$ Maryam Tabrizian, ${ }^{2}$ \\ Arnold Scott Kristof, ${ }^{1}$ Irah Luther King, ${ }^{1}$ Luis Bruno Barreiro, ${ }^{3}$ and Maziar Divangahi ${ }^{1}$ \\ 'Department of Medicine, Department of Microbiology and Immunology, Department of Pathology, McGill International TB Centre, McGill University Health Centre, Montreal, Quebec, Canada. \\ ${ }^{2}$ Department of Biomedical Engineering, McGill University, Montreal, Quebec, Canada. ${ }^{3}$ Sainte-Justine Hospital Research Centre, Department of Pediatrics, and ${ }^{4}$ Department of Anatomy and Cell Biology, \\ Faculty of Medicine, University of Montreal, Quebec, Canada.
}

\begin{abstract}
The phagocytosis of apoptotic cells and associated vesicles (efferocytosis) by DCs is an important mechanism for both self tolerance and host defense. Although some of the engulfment ligands involved in efferocytosis have been identified and studied in vitro, the contributions of these ligands in vivo remain ill defined. Here, we determined that during Mycobacterium tuberculosis (Mtb) infection, the engulfment ligand annexin1 is an important mediator in DC cross-presentation that increases efferocytosis in DCs and intrinsically enhances the capacity of the DC antigen-presenting machinery. Annexin1-deficient mice were highly susceptible to Mtb infection and showed an impaired Mtb antigen-specific CD8+ $T$ cell response. Importantly, annexin1 expression was greatly downregulated in Mtb-infected human blood monocyte-derived DCs, indicating that reduction of annexin1 is a critical mechanism for immune evasion by $M t b$. Collectively, these data indicate that annexin1 is essential in immunity to Mtb infection and mediates the power of DC efferocytosis and cross-presentation.
\end{abstract}

\section{Introduction}

$\mathrm{CD}^{+} \mathrm{T}$ cells are essential in resistance to Mycobacterium tuberculosis $(M t b)(1-3)$. Despite the fact that $M t b$ is a phagosomal pathogen and initiates antigen presentation via the MHC class II (MHC-II) endocytic pathway, $M t b$ antigens also access the MHC-I-restricted pathway by a mechanism termed cross-presentation $(4,5)$. This mechanism allows antigen-presenting cells (APCs), mainly DCs, to efficiently present antigens of exogenous origins to MHC-Irestricted $\mathrm{CD}^{+} \mathrm{T}$ cells (6). Several studies have demonstrated that phagocytosis of apoptotic cells, a process called efferocytosis, is an important source of antigens for cross-presentation by DCs (7-10). Kaufmann's group further showed that engulfment of apoptotic vesicles released from $M t b$ - or bacillus Calmette-Guerin-infected (BCG-infected) macrophages by DCs leads to $\mathrm{CD} 8^{+} \mathrm{T}$ cell activation $(11,12)$. In line with these findings, we have demonstrated that $M t b$ evades host immunity by inhibiting apoptosis and promoting necrosis in infected macrophages (13-15). Importantly, increased apoptosis in $M t b$-infected macrophages initiates an early protective immunity to pulmonary tuberculosis (16). Although the role of apoptosis in $M t b$ infection has been widely studied, our understanding of the mechanisms involved in selective recognition and uptake of apoptotic cells/vesicles (efferocytosis) by DCs for crosspresentation is still very limited.

A recent study by Behar's group demonstrated that apoptosis per se is not intrinsically bactericidal, but is dependent on effero-

Conflict of interest: The authors have declared that no conflict of interest exists Submitted: May 23, 2014; Accepted: November 13, 2014

Reference information: J Clin Invest. 2015;125(2):752-768. doi:10.1172/JCI77014. cytosis by macrophages to control $M t b$ growth (17). Whereas macrophages are highly efficient in efferocytosis and play an important role in innate immunity to $M t b(17)$, little is known about the mechanism or mechanisms of efferocytosis by DCs as well as its contribution to immunity against $M t b$. Similar to macrophages, efferocytosis by DCs depends on the expression of engulfment ligands, also known as "eat-me" signals, on the surface of dying cells and multiple receptors on the surface of phagocytic cells. These receptors can directly interact with apoptotic cells, but most interactions occur indirectly through bridging proteins (18). The best characterized eat-me signal is the exposure of phosphatidylserine (PS) at the outer leaflet of the plasma membrane (19). Although necessary, PS alone is not efficient in triggering engulfment. Thus, other eat-me signals are required for an optimum uptake of apoptotic cells (20). Though in vitro studies have identified several classes of receptors implicated in efferocytosis (21-23), knowledge of the engulfment ligands and molecular mechanisms involved in DC efferocytosis as well as cross-presentation in vivo continues to represent a major gap in our understanding of this important phenomenon.

Annexin1 (encoded by ANXA1) is a member of the annexin protein superfamily and binds to negatively charged phospholipid membranes in a calcium-dependent manner (24). The N-terminal portion of annexin 1 confers its unique biological characteristics, with a wide spectrum of biological functions. In addition to its very well-described antiinflammatory role $(25,26)$, colocalization of PS with annexin 1 on the surface of apoptotic cells enhances recognition, tethering. and internalization of apoptotic cells by endothelial cells (27). Additionally, annexin1 has recently been shown to be a key modulator of adaptive immunity through its ability to 
A
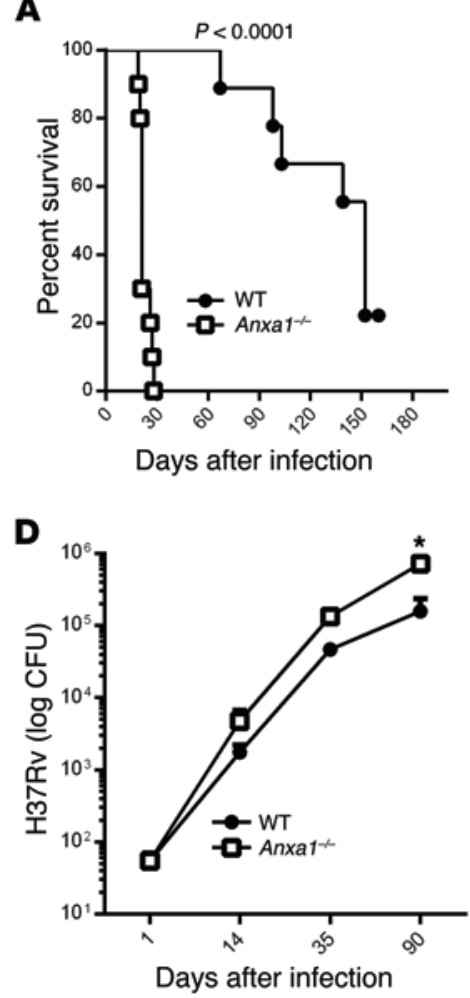

B

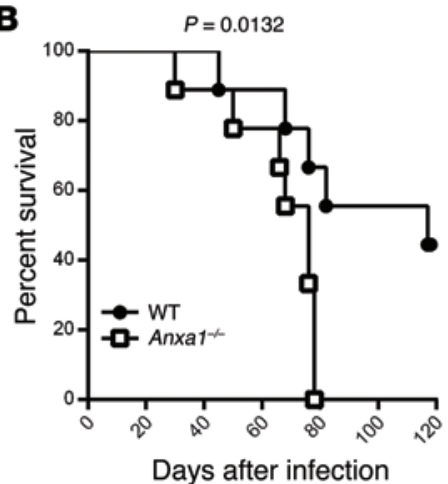

E

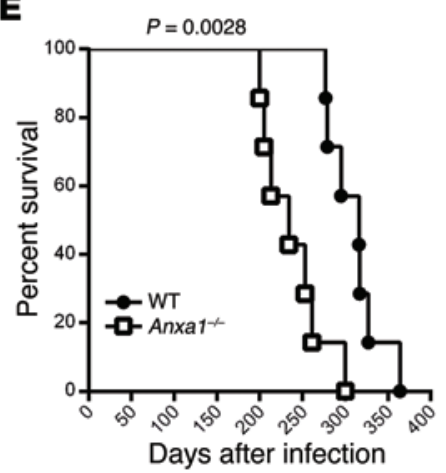

C

C Day 20

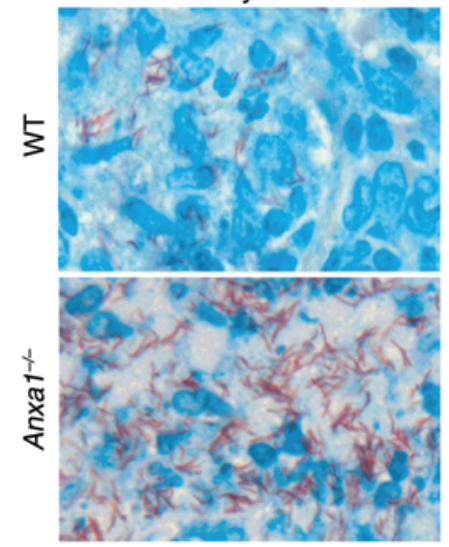

Figure 1. Anxa1-/- mice are highly susceptible to Mtb infection. (A and B) Survival of WT and Anxa1 ${ }^{-/-}$mice ( $\left.n=9-10 / g r o u p\right)$ infected i.v. with approximateIy $10^{8}(\mathbf{A})$ or approximately $10^{6}$ (B) virulent Mtb bacilli. (C) Lung tissues from WT (upper panel) and Anxa1 $1^{-/-}$(lower panel) mice stained with Ziehl-Neelsen for detection of $\mathrm{Mtb}$ bacilli after 20 days infection (i.v.) with approximately $10^{8}$ virulent Mtb. Original magnification, $\times 40$. (D) Bacterial burden in the lungs after 14, 35, and 90 days of aerosol infection with Mtb ( $n=5 /$ group). (E) Survival of WT and Anxa1/- mice ( $n=7 /$ group) after aerosol infection with virulent Mtb. ${ }^{*} P<0.05$ (1-way ANOVA). Survival data were analyzed by log-rank test.

control T cell activation $(28,29)$. Annexin1 expression has been associated with a variety of inflammatory diseases (cystic fibrosis and ulcerative colitis), autoimmune diseases (rheumatoid arthritis and lupus erythematous), and cancer (30), but its role in infectious diseases is poorly understood.

A recent study by Gan and colleagues (31) indicated that in macrophages infected with the virulent strain of $M t b$, the amino terminal of annexin 1 is removed, resulting in proteolytic truncation of annexin1 and loss of its biological activities in vitro. In the current study, we sought to determine the role of annexin1 during the course of $M t b$ infection in vivo. We found that annexin1-deficient mice $\left(A n x a 1^{--}\right)$were remarkably more susceptible to pulmonary $M t b$ infection than WT mice. The high levels of pulmonary bacterial burden and mortality in Anxa1 $1^{--}$mice were associated with reduced $M t b$ antigen-specific $C D 8^{+} \mathrm{T}$ cell responses in the lung. By generating chimeric mice that selectively lack annexin 1 in $\mathrm{T}$ cells, we have shown that the reduction of $M t b$ antigen-specific $C D 8^{+} \mathrm{T}$ cells is extrinsic to the $\mathrm{T}$ cell compartment. Interestingly, both in vitro and in vivo, annexin1-deficient DCs demonstrated a markedly reduced capacity to cross-present antigens to $\mathrm{CD} 8^{+} \mathrm{T}$ cells. The reduced capacity of annexin1-deficient DCs for cross-presentation was due to (a) the critical role of annexin1 in efferocytosis and (b) the intrinsic role of annexin1 in antigen-processing machinery. Importantly, infection of human blood monocyte-derived DCs with $M t b$ induced a downregulation of annexin1 gene expression, and genome-wide gene expression shows a strong correlation between annexin1 and biological pathways involved in endosome, lysosome, and autophagy. Furthermore, we showed that annexin1 is required for an optimal autophagy, suggesting an important link among annexin1, autophagy, and cross-presentation in DCs. Collectively, these data identify annexin 1 as a central player in protective immunity against $M t b$ infection, primarily by regulating the power of DC cross-presentation.

\section{Results}

Anxa1 ${ }^{--}$mice are highly susceptible to Mtb infection. To investigate the role of annexin 1 during $M t b$ infection, we initially evaluated survival of WT and annexin1-deficient mice (Anxa1 $\left.1^{--}\right)$infected i.v. with a high dose $\left(10^{8} \mathrm{CFU}\right)$ or low dose $\left(10^{6} \mathrm{CFU}\right)$ of virulent $M t b(\mathrm{H} 37 \mathrm{Rv})$. Anxa1 $1^{-/-}$mice were highly susceptible to $M t b$ infection, and all succumbed to death (Figure 1, A and B). This increased susceptibility of Anxa1 $1^{-/}$mice to infection was corroborated with higher numbers of pulmonary $M t b$ (Figure 1C). We next infected WT and Anxa1 $1^{-/-}$mice with a low dose (50-100 CFU) of H37Rv via an aerosol route to assess both pulmonary bacterial burden and survival. Similar to the i.v. model, Anxa1 $1^{-/-}$mice showed higher bacterial burden at 35 and 90 days after infection (Figure 1D). This impaired control of bacterial growth in Anxa1 $1^{-/-}$ mice correlated with a significant decrease in survival (Figure 1E). Analyses of histopathology indicated that lungs of Anxa1 $1^{-/-}$mice were affected with a diffuse chronic active histiocytic pneumonitis (Supplemental Figure 1A; supplemental material available online 
A

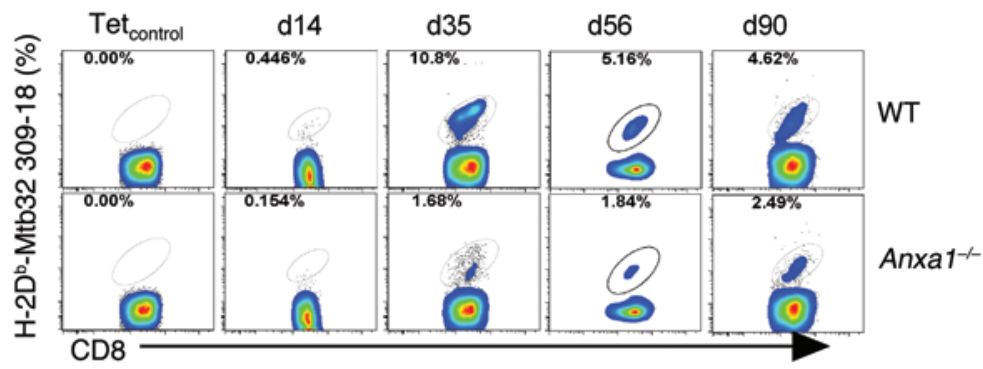

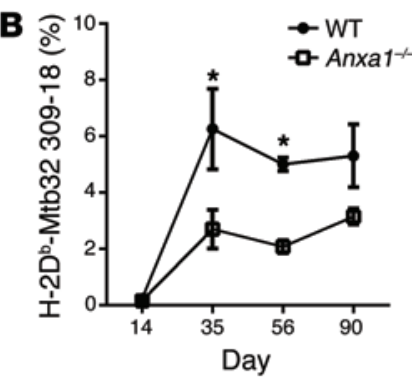

C
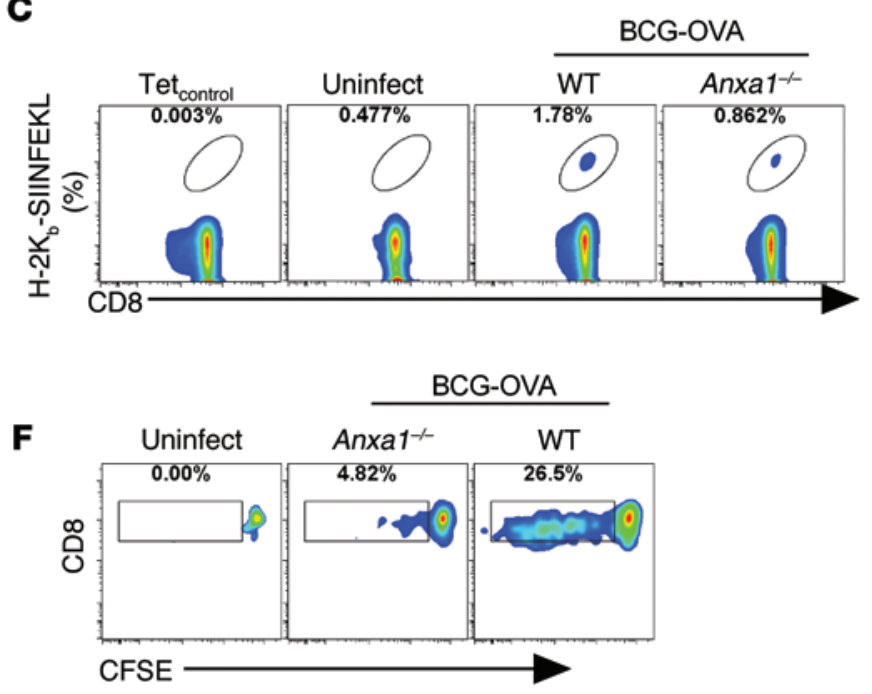
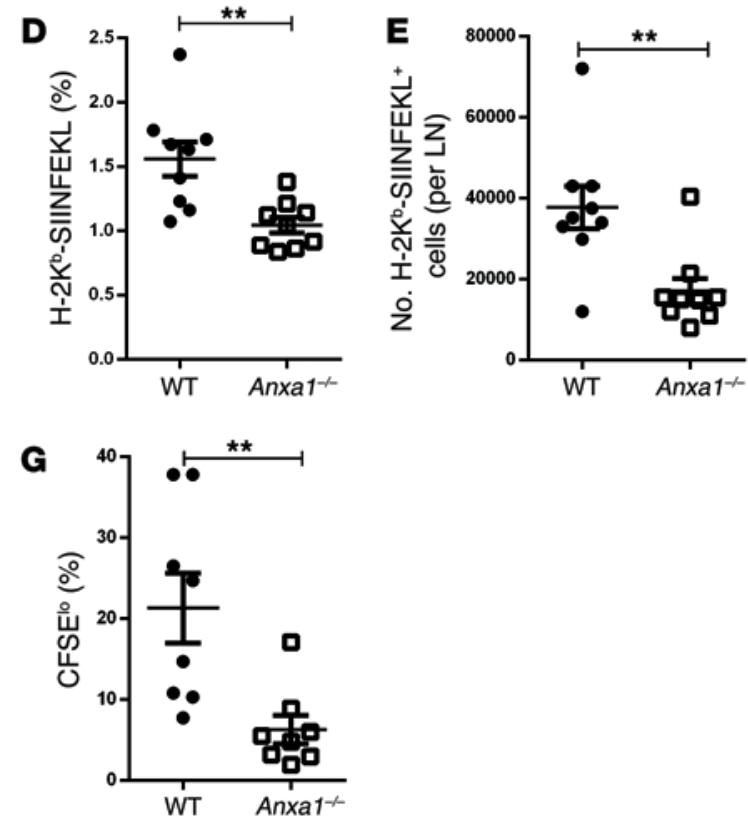

Figure 2. Anxa1 1/- mice have reduced Mtb antigen-specific CD8+ $\mathbf{T}$ cell responses to Mtb infection. (A and B) Frequency of Mtb32 309-18-specific CD8 ${ }^{+}$ T cells in the lungs of WT and Anxa1/- mice ( $n=5$ /group) after 14, 35, 56, and 90 days of aerosol infection with virulent Mtb (30-50 CFU). PE-conjugated streptavidin was used as a control for the tetramer staining. Numbers above outlined areas $(\mathbf{A})$ indicate the percentage of $\mathrm{CD} 8^{+} \mathrm{T}$ cells stained with $\mathrm{H}-2 \mathrm{D}^{\mathrm{b}}-$ Mtb32 309-18. Results of 2 independent experiments are pooled. ${ }^{*} P<0.05$ ( $t$ test). (C-G) CFSE-labeled OT-I TCR-transgenic CD8 ${ }^{+}$T cells were adoptively transferred to WT or Anxa1-/- mice (i.v.). The following day, mice were infected (footpad) with BCG-OVA. Frequency (C and $\mathbf{D})$ and total cell number (E) of SIINFEKL-specific CD8 ${ }^{+} T$ cells and T cell proliferation (F and $\left.\mathbf{G}\right)$ from draining popLNs at day 4 after infection. Numbers above outlined areas (C) indicate the percentage of $\mathrm{CD}^{+} \mathrm{T}$ cells stained with $\mathrm{H}-2 \mathrm{~K}^{\mathrm{b}}-\mathrm{SIINFEKL}$; numbers above gate $(\mathbf{F})$ indicate the percentage of $\mathrm{CFSE}{ }^{10}$ cells. Each symbol represents an individual mouse. Results are pooled from 2 independent experiments $\left(n=4-5 /\right.$ group). ${ }^{*} P<0.05 ;{ }^{* *} P<0.01$ ( $t$ test).

with this article; doi:10.1172/JCI77014DS1), with large numbers of stainable mycobacterial organisms (Supplemental Figure 1B). Together, these results indicate that annexin1 plays a critical role in protection against $M t b$ infection.

Anxa1 ${ }^{-1-}$ mice have an impaired antigen-specific $C D 8^{+} T$ cell response. Both $\mathrm{CD} 4^{+}$and $\mathrm{CD} 8^{+} \mathrm{T}$ cells are important effectors in protective immunity against $M t b(1-3,32)$. We next assessed the quantity of pulmonary T cells in WT and Anxa1 ${ }^{--}$mice after aerosol infection with virulent $M t b$. There was no significant difference in the frequency of $\mathrm{CD} 4^{+}$or $\mathrm{CD} 8^{+} \mathrm{T}$ cells (Supplemental Figure 1, $\mathrm{C}$ and $\mathrm{D})$. However, the frequency of Mtb32-specific $\mathrm{CD} 8^{+} \mathrm{T}$ cells was significantly reduced in the lungs of Anxa1 $1 /$ mice compared with WT mice at days 35 and 56 after infection (Figure 2, A and B). We next investigated whether infection with an avirulent strain would also result in reduced antigen-specific $\mathrm{T}$ cell responses in Anxa1 $1^{-/}$mice. We adoptively transferred (i.v.) CFSE-labeled OT-I TCR-transgenic $\mathrm{CD}^{+} \mathrm{T}$ cells, which are specific to OVA peptide (SIINFEKL), to WT and Anxa1 ${ }^{-/-}$mice, followed by a footpad infection with the recombinant BCG-expressing OVA (BCG-OVA) 1 day later. Four days after infection, we detected a significantly smaller population of SIINFEKL-specific $\mathrm{CD}^{+} \mathrm{T}$ cells in the draining popliteal lymph nodes (popLN) of infected Anxa1-- mice compared with WT mice (Figure 2, C and D). Consistent with reduced expansion of SIINFEKL-specific CD8 ${ }^{+} \mathrm{T}$ cells in Anxa1 ${ }^{-1}$ mice, the proliferation of SIINFEKL-specific $\mathrm{CD} 8^{+} \mathrm{T}$ cells was also significantly decreased, as measured by the percentage of $\mathrm{CFSE}^{\mathrm{lo}} \mathrm{CD}^{+}$ $\mathrm{T}$ cells (Figure 2, $\mathrm{F}$ and $\mathrm{G}$ ). Collectively, these results indicate that following mycobacterial infection, there was a substantial reduction in antigen-specific $\mathrm{CD} 8^{+} \mathrm{T}$ cells in the absence of annexin1.

Annexin1 has no intrinsic role in $T$ cells during Mtb infection. It has been previously shown that annexin1 can act as a "tuner" to modulate the strength of TCR signaling, leading to increased T cell proliferation $(28,29)$. As both the quantity and quality of the $\mathrm{T}$ cell response are important for the control of $M t b$ infection, we next determined whether annexin1 directly affects $\mathrm{T}$ cell function or expansion in vivo. To this end, we infected mice with BCG-OVA 
A

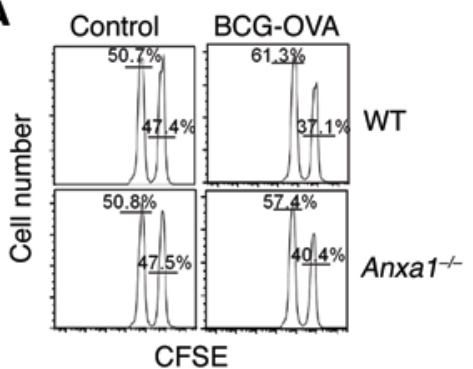

C

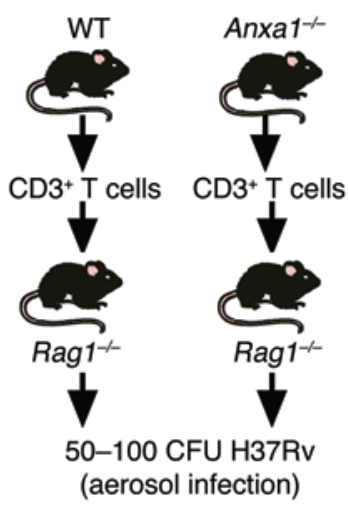

$\mathbf{F}$

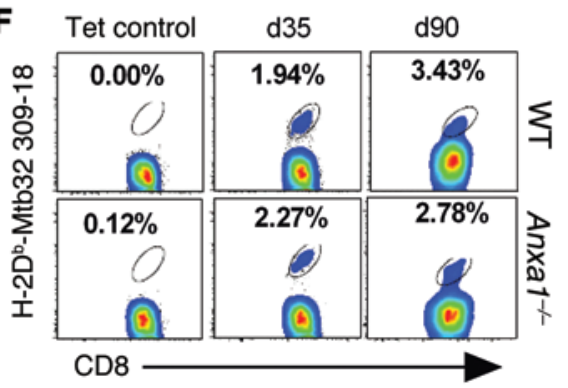

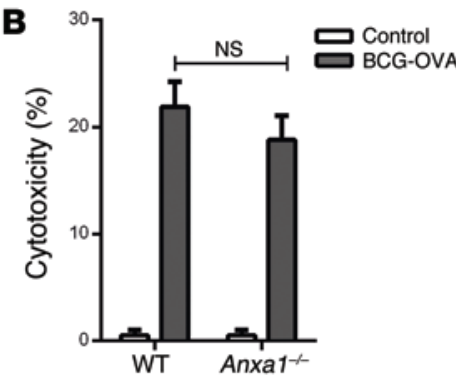
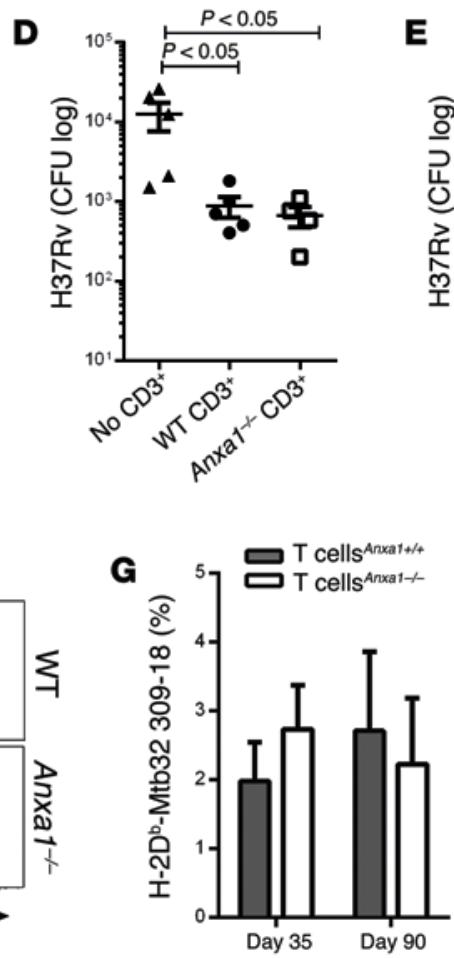

Figure 3. Expression of annexin1 in T cells is not required for resistance to pulmonary Mtb infection. (A and B) In vivo cytotoxic activity against target cells coated with OVA peptide (SIINFEKL) in WT and Anxa1 $1^{-1-}$ mice $(n=4$ / group) at day 14 after i.v. infection with BCG-OVA. Numbers above bracketed lines (A) indicate the percentage of unpulsed CFSE' ${ }^{10}$ (left) and SIINFEKL-coated CFSE ${ }^{\text {hi }}$ (right) cells. (B) Percentage of elimination of target cells coated with SIINFEKL was calculated as described in Methods. (C) Rag-deficient mice were used as recipients for splenic

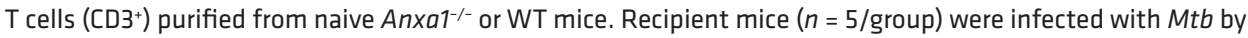
the aerosol route within 24 hours after transfer of purified T cells. Bacteria burden in the lungs (D) and spleen (E) after 3 weeks of infection. Each symbol represents an individual mouse. Data are representative of 2 independent experiments. $P<0.05$, 1-way ANOVA. $(\mathbf{F}-\mathbf{H})$ Mixed BM chimeric mice were generated as described in Methods. Twelve weeks after reconstitution, mice were infected via aerosol route with virulent $M t b$. Frequency of Mtb32-

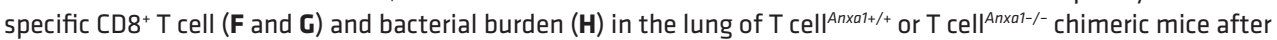
35 and 90 days of Mtb infection. PE-conjugated streptavidin was used as a control for the tetramer staining. (H) Numbers above outlined areas indicate the percentage of $C D 8^{+} \mathrm{T}$ cells stained with $\mathrm{H}-2 \mathrm{~K}^{\mathrm{b}}-\mathrm{SIINFEKL}$. Ten mice/ group were individually analyzed. There was no significant difference between groups ( $t$ test).

and measured the cytotoxic activity of $\mathrm{CD}^{+} \mathrm{T}$ cells in vivo. Two weeks after infection, splenic SIINFEKL-specific $\mathrm{CD}^{+} \mathrm{T}$ cells from WT and Anxa1 ${ }^{-/-}$mice showed comparable ability to eliminate target cells pulsed with OVA peptide (SIINFEKL; Figure 3, A and $\mathrm{B})$. To evaluate the protective capacity of $\mathrm{T}$ cells in the presence or absence of annexin1 against pulmonary infection with virulent $M t b$, we adoptively transferred (i.v.) equal numbers of purified naive $\mathrm{CD}^{+} \mathrm{T}$ cells from WT or Anxa1 ${ }^{-/-}$mice to Rag-deficient recipient mice. Quantitative PCR confirmed that the expression of the annexin1 gene was disrupted in Anxa1 $1^{-/} \mathrm{T}$ cells. Importantly,
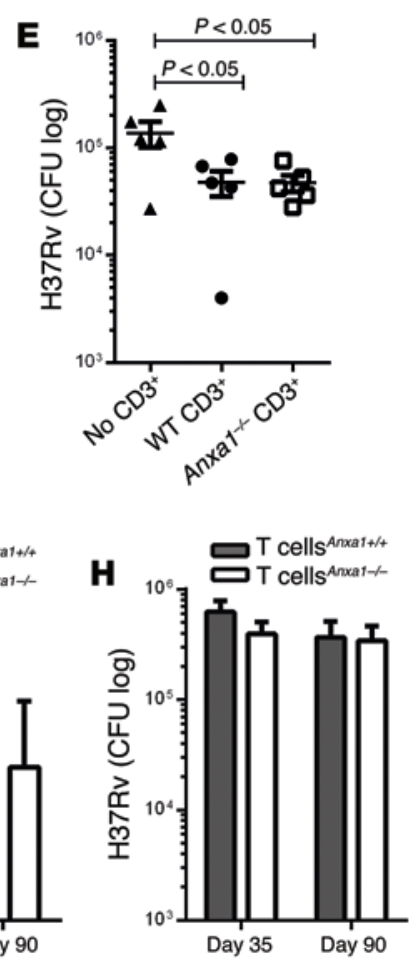

the absence of annexin1 had no effect on the expression of other annexin family members or genes involved in eicosanoid pathways (Supplemental Figure 2A). One day after T cell transfer, recipient mice were infected with $M t b$ by aerosol (Figure 3C). Three weeks after infection, we detected no difference in bacterial burden in the lungs or spleens of recipient mice that received WT or Anxa1 ${ }^{-1} \mathrm{~T}$ cells (Figure 3, D and E). To further rule out the potential intrinsic role of annexin1 in T cells, we generated chimeric mice in which only $\mathrm{T}$ cells lacked annexin1 ( $\mathrm{T}$ cell ${ }^{\text {Anxal-/ }}$ chimeric mice). As shown in Supplemental Figure $2 \mathrm{~B}$, irradiated $\alpha / \beta \mathrm{T}$ cell receptor-deficient mice $\left(\mathrm{Tcra}^{-/}\right)$ were reconstituted with BM cells from $\mathrm{Tcra}^{-/-}$and Anxa1 $1^{-/-}$mice mixed in a $4: 1$ ratio, respectively. Thus, $\mathrm{T}$ cells in reconstituted $\mathrm{T}$ cell $^{\text {Anxal-/- }}$ mice are only derived from Anxa1 $1^{-/}$precursors, whereas the non- $\mathrm{T}$ cells are predominantly Anxa1 ${ }^{+/+}$. Control chimeric mice were generated in an equivalent manner by using a BM mixture from $\mathrm{Tcra}^{-/-}$mice and WT littermates ( $\mathrm{T}$ cell ${ }^{\text {Anxal+/+ }}$ chimeric mice). Twelve weeks after reconstitution, by using real-time PCR, we confirmed the absence of annexin 1 in $\mathrm{T}$ cells purified from $\mathrm{T}$ cell ${ }^{\text {Anxal-/- }}$ mice (Supplemental Figure 2C). Considering that a small fraction of APCs were annexin1 deficient in $\mathrm{T}$ cell ${ }^{\text {Anxal-/- }}$ mice, we next generated $\mathrm{BM}$-derived DCs (BMDCs) from both groups of chimeric mice to evaluate their functions. Upon LPS stimulation, there were no significant differences in costimulatory molecule expression (Supplemental Figure 2D) or cytokine production (Supplemental Figure 2E), indicating there were no defects in DCs from the chimeric animals. To evaluate $\mathrm{T}$ cell responses as well as bacterial growth, we infected (aerosol) chimeric mice with virulent $M t b$. The proportions of total $\mathrm{CD} 4^{+} \mathrm{T}$ and $\mathrm{CD} 8^{+} \mathrm{T}$ cells in the lungs of $\mathrm{T}$ cell ${ }^{\text {Anxal } / /-}$ mice were equivalent to those of $\mathrm{T}$ cell ${ }^{\text {Anxal+/+ }}$ chimeric mice at different time points after infection, indicating that both groups were similarly reconstituted (Supplemental Figure 2, F and $\mathrm{G})$. We did not find differences in the frequency of Mtb32-specific 
A

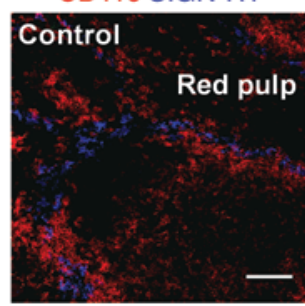

CD8 SIGN-R1

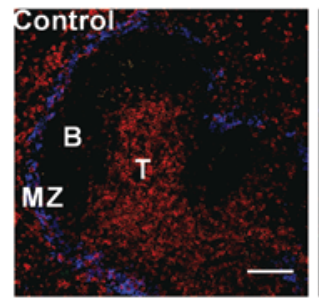

B
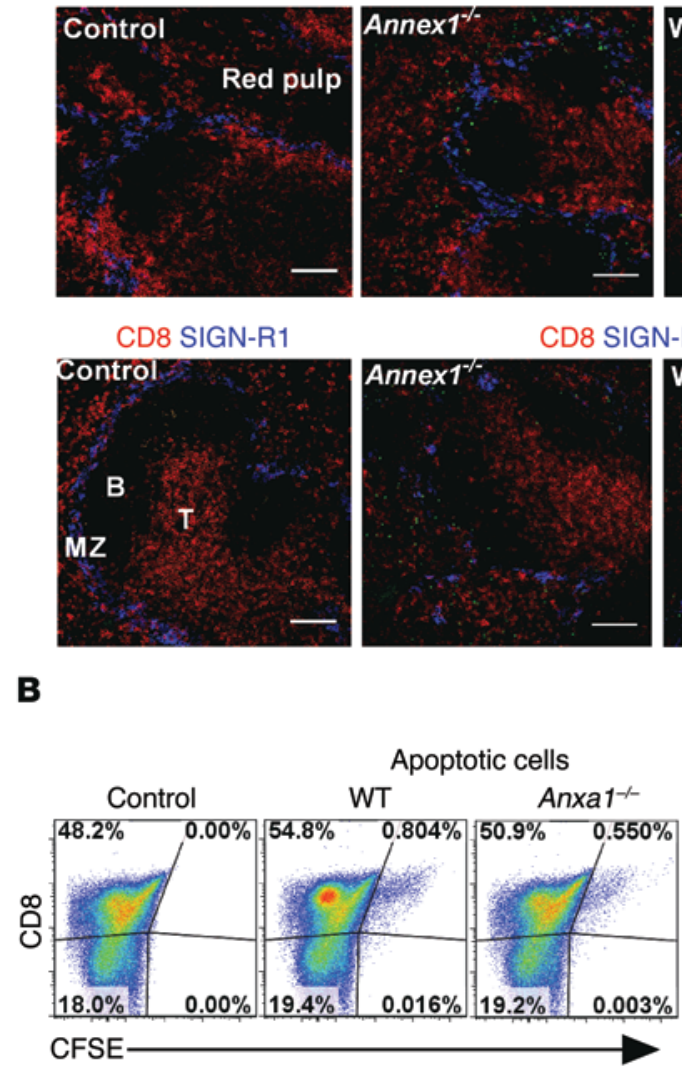

CD11C SIGN-R1 CFSE
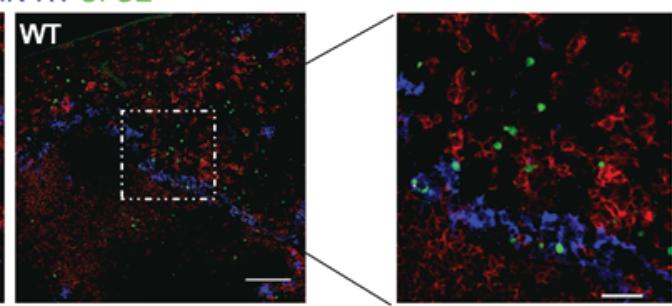

CD8 SIGN-R1 CFSE
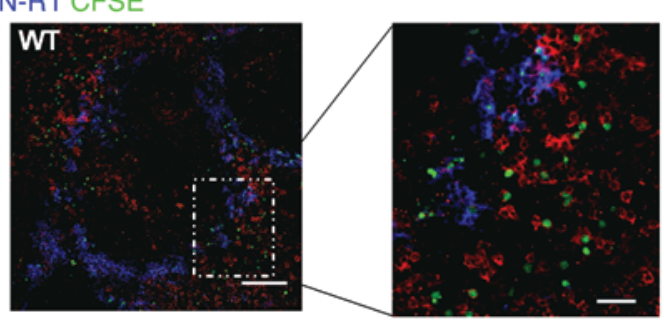

C

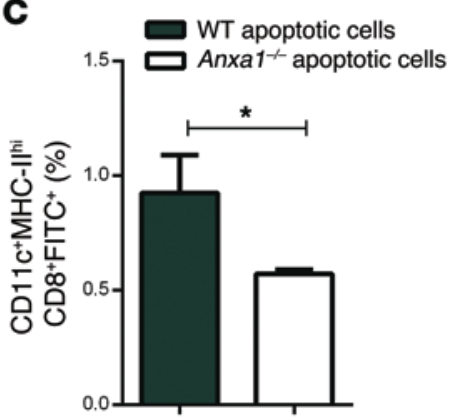

Figure 4. Expression of annexin1 on apoptotic cells regulates efferocytosis. (A-D) CFSE-labeled WT or Anxa1 $1^{-/-}$apoptotic cells were injected (i.v.) into WT mice ( $n=3$ /group). (A) After 1 hour, localization of injected apoptotic cells was examined in the sections of spleen. The sections were stained with anti-CD11c or anti-CD8 (red) and SIGN-R1 (blue marginal zone [MZ] macrophages). Scale bars: $100 \mu \mathrm{m}$. The white squares are enlarged views showing the majority of CFSE-labeled apoptotic cells (green) were localized with either CD11c ${ }^{+}$or CD8 ${ }^{+}$cells in red pulp. Scale bars: 30 Hm. B, B cells; T, T cells. (B-D) CFSE-labeled apoptotic cells were selectively taken up by CD8+CD11c $\mathrm{CCs}$. One hour after injection of apoptotic cells, splenic DCs were enriched with positive selection and CD8+ DCs were gated from the CD11C ${ }^{+}$MHC-II hi population. Frequency (B and C) and total number (D) of CD8+ DCs that engulfed apoptotic cells. ${ }^{*} P<0.05$ ( $t$ test).

$\mathrm{CD}^{+} \mathrm{T}$ cells (Figure $3, \mathrm{~F}$ and $\mathrm{G}$ ) or bacterial burden in the lungs (Figure $3 \mathrm{H}$ ) or spleens (Supplemental Figure $2 \mathrm{H}$ ) from either group of chimeric mice. Thus, annexin1 expression in T cells is dispensable for protection against pulmonary $M t b$ infection.

Expression of annexin1 on apoptotic vesicles enhances DC efferocytosis and the T cell response. Previous studies from our and other groups $(11,16,33)$ have shown that increased apoptosis in $M t b-$ infected macrophages enhances $\mathrm{T}$ cell-mediated immunity via cross-presentation. Furthermore, a study by Gan and colleagues revealed that annexin 1 is essential for forming the apoptotic envelope (31). Therefore, we investigated whether differences in the macrophage cell death program could be responsible for reducing protection against $M t b$ in $A n x a 1^{-/-}$mice. We infected BM-derived macrophages (BMDMs) from WT and Anxa1/- mice with different MOI of virulent $M t b$ in vitro and evaluated the cell death program. Two days after infection, both groups of macrophages presented equivalent levels of apoptosis and necrosis, as measured by a cell death ELISA (Supplemental Figure 3, A and B). Similarly, there was no significant difference in necrosis $\left(7 \mathrm{AAD}^{+}\right)$or apoptosis $\left(\right.$ annexin $\left.\mathrm{V}^{+} 7 \mathrm{AAD}^{-}\right)$of $\mathrm{BMDMs}$ infected with avirulent strain H37Ra (Supplemental Figure 3, C-E).
Efferocytosis is also a source of antigens for $\mathrm{CD} 8^{+} \mathrm{T}$ cells via cross-presentation $(8,12)$. Since annexin 1 expression on the surface of apoptotic cells can act as a ligand that mediates engulfment in vitro (27), we next determined whether the presence of annexin1 on the surface of apoptotic cells is important for the recognition and uptake by DCs in vivo. Splenocytes from WT or Anxa1 ${ }^{-/-}$mice were labeled with CFSE, subjected to osmotic shock to induce apoptosis (34), and injected (i.v.) into recipient WT mice. Similar to findings in the previous study by Iyoda and colleagues (34), $\mathrm{CFSE}^{+}$apoptotic cells were found within both $\mathrm{CD} 11 \mathrm{c}^{+}$and $\mathrm{CD} 8^{+}$ DCs located just outside of the splenic marginal zone, a region delineated by SIGN-R1 ${ }^{+}$marginal zone macrophages (Figure $4 \mathrm{~A})$. These results suggested that $\mathrm{CD} 8^{+} \mathrm{DCs}$, a dominant source of cross-presenting APCs (34), were able to take up and process apoptotic bodies. To quantify this observation, CD11c $\mathrm{C}^{+} \mathrm{MC}-\mathrm{II}^{\mathrm{hi}}$ DCs were enriched from the spleens of recipient WT mice by CD11c-positive selection (Supplemental Figure 5A) and assessed by flow cytometry. As shown in Figure 4B, only the CD8 ${ }^{+}$subset of DCs had taken up $\mathrm{CFSE}^{+}$apoptotic cells. Importantly, the frequency and total number of $\mathrm{CD}^{+} \mathrm{DC}^{\mathrm{WT}}$ that engulfed WT apoptotic cells were significantly higher than $C D 8^{+} D C^{\text {WT }}$ that engulfed 
A
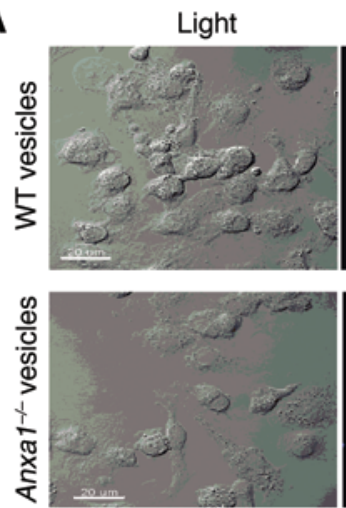

Nuclei
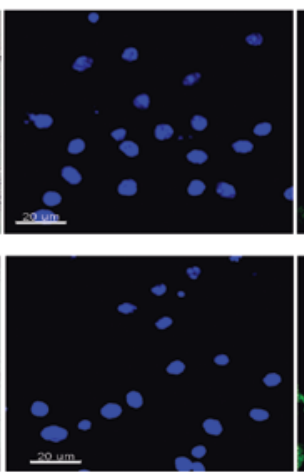

Actin
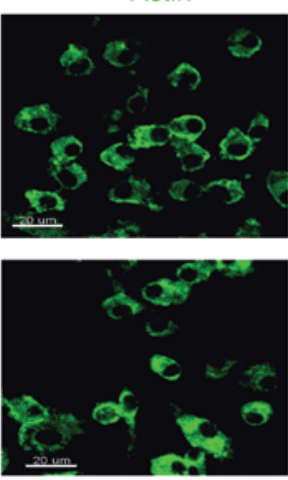

Vesicles
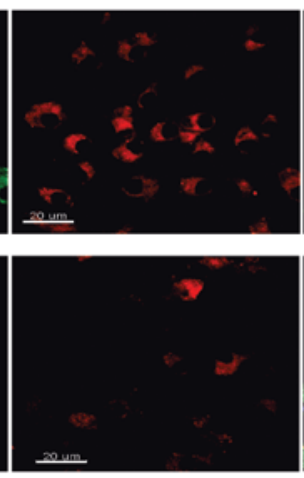

Merged
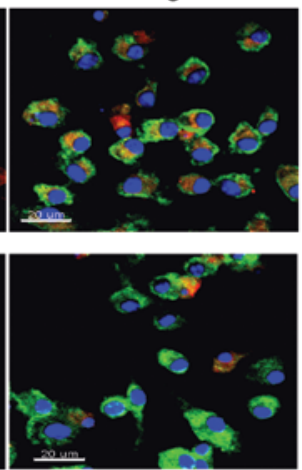

B

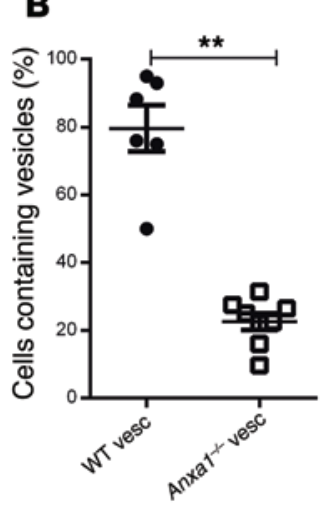

C

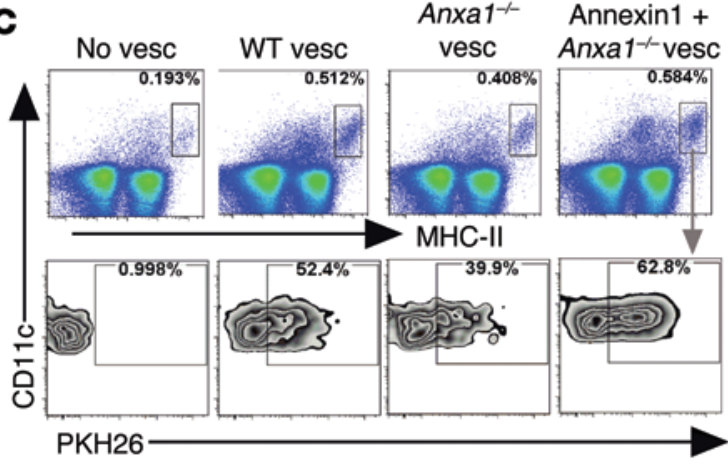

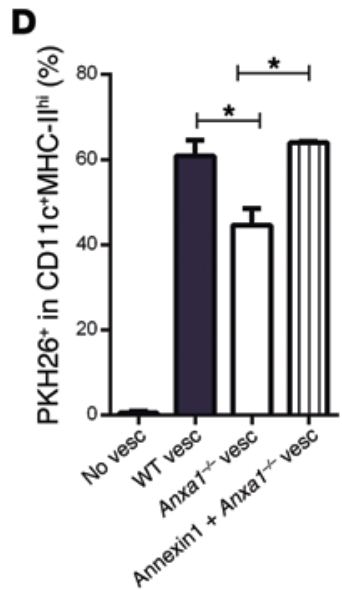

E

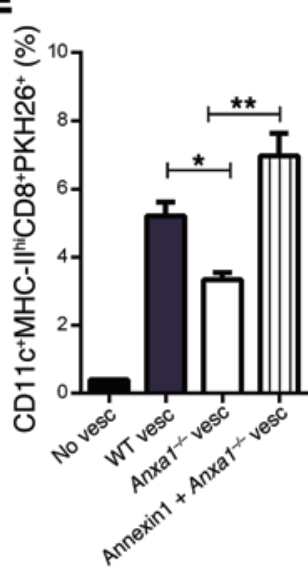

Figure 5. Expression of annexin1 on apoptotic vesicles regulates efferocytosis. (A and B) In vitro efferocytosis assay with WT BMDCs. (A) Confocal microscopy of WT BMDCs (DCWT) incubated with PKH26-labeled WT (upper panel) or Anxa1 ${ }^{-/-}$(bottom panel) apoptotic vesicles (red). DCWT were stained for $\mathrm{F}$-actin (green) and nuclei (blue). The right pictures represent an overlay demonstrating the presence of red vesicles in the cytoplasm of DCWT. Scale bars: $20 \mu \mathrm{m}$. (B) Percentage of DCWT-containing vesicles in the cytoplasm. Results are representative of 2 independent experiments. ${ }^{* *} P<0.01$ ( $t$ test). (C-E) PKH26-labeled WT or Anxa1-/- vesicles mixed or not with recombinant annexin1 were injected into the footpad of WT mice ( $n=3 / g r o u p)$. (C, upper panels). Frequency of DCs (CD11 $\left.\mathrm{C}^{+} \mathrm{MHC}-\mathrm{II}^{\mathrm{h}}\right)$ from popLNs after 24 hours of injection of apoptotic vesicles. Frequency of DCs (C, lower panels, and $\left.\mathbf{D}\right)$ and CD8 ${ }^{+}$DCs $(\mathbf{E})$ positive for PKH26. Numbers above outlined areas (C, upper panels) indicate the percentage of CD11 ${ }^{+}$MHC-IIhi cells. Numbers above gates (C, lower panels) indicate the percentage of $\mathrm{CD} 11 \mathrm{c}^{+} \mathrm{PKH} 2 \mathrm{G}^{+}$cells. ${ }^{*} P<0.05$ ( $t$ test).

Anxa1 ${ }^{-/}$apoptotic cells (Figure 4, C and D). To further support the importance of annexin1 on apoptotic cells for efferocytosis, we next injected CFSE-labeled apoptotic splenocytes from WT mice into WT or Anxa1 ${ }^{-/}$mice. As all donor apoptotic cells contained annexin1, no significant differences were observed in the uptake of apoptotic cells between $\mathrm{CD} 8^{+} \mathrm{DC}{ }^{\mathrm{WT}}$ and $\mathrm{CD} 8^{+} \mathrm{DC}^{\text {Anxal-- }}$ (Supplemental Figure 6, B-D).

We next evaluated whether the presence of annexin 1 on the surface of apoptotic vesicles released from mycobacterialinfected macrophages is also important for the recognition and uptake by DCs. Apoptotic vesicles were purified from WT or Anxa1 ${ }^{-1-}$ BMDMs infected with BCG-OVA. No difference in bacterial burden was observed between WT and Anxa1 ${ }^{-1-}$ BMDMs (Supplemental Figure 4A), and there were no viable bacteria in apoptotic vesicles, while OVA protein was detectable by Western blot (data not shown). Scanning electron microscopy revealed vesicle formation of WT and Anxa1 ${ }^{--}$BMDMs undergoing infectioninduced apoptosis (Supplemental Figure 4B), and the absence of annexin1 on the membrane of Anxa1 ${ }^{-/}$vesicles was confirmed by Western blot (Supplemental Figure 4C). Considering exosomes also can transfer antigens for cross-presentation independently of apoptotic vesicles (35), we further characterized the vesicles in our study. Using flow cytometry, we found that the size of WT and Anxa1-- vesicles was similar (Supplemental Figure 4, D and E). WT and Anxa1 ${ }^{-/-}$vesicles presented a heterogeneous population, with the majority of vesicles in the range of $0.22 \mu \mathrm{m}$ (Supplemental Figure 4E). Similarly, analysis by a particle sizer using a low-angle laser light-scattering device indicated that the size of vesicles was approximately $0.1-0.2 \mu \mathrm{m}$ in WT and Anxa1 ${ }^{-/}$vesicles, as indicated by size and polydispersity(Supplemental Figure $4 \mathrm{~F})$. Both vesicles presented a negative surface charge, as expected (zeta potential; Supplemental Figure 4F). Finally, detection of surface phosphatidylserine by annexinV confirmed that both WT and Anxa1 $1^{-/}$purified vesicles were derived from apoptotic cells (Supplemental Figure 4G) and were not exosomes.

To determine whether efferocytosis by DCs is modulated by vesicular expression of annexin1, WT and Anxa1 ${ }^{-/-}$vesicles were labeled with PKH26 fluorochrome and incubated separately with WT BMDCs ( $\mathrm{DC}^{\mathrm{WT}}$ ). After 30 minutes of incubation, $\mathrm{DC}^{\mathrm{WT}}$ were stained with Hoechst and Alexa Fluor 488-conjugated phalloidin 
A

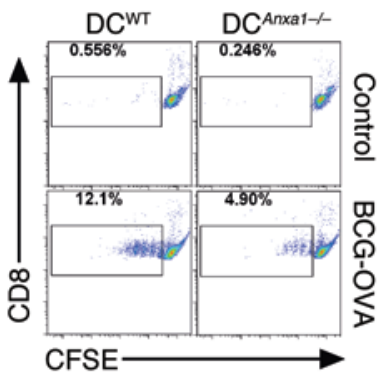

B

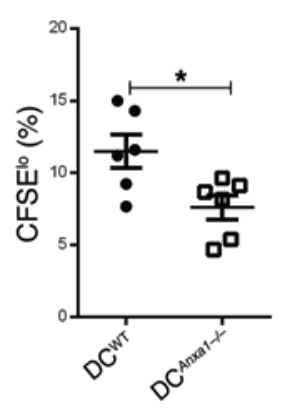

C

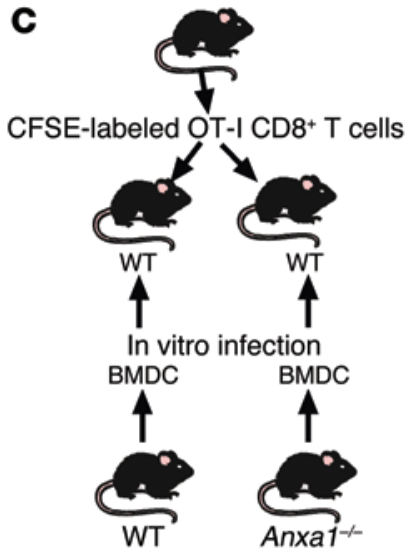

D

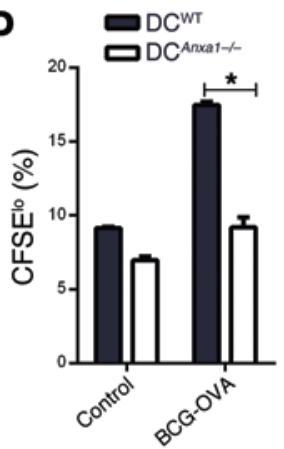

E

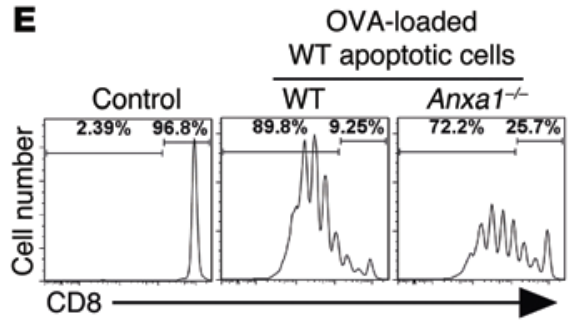

$\mathbf{F}$

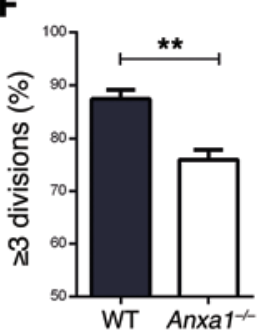

G

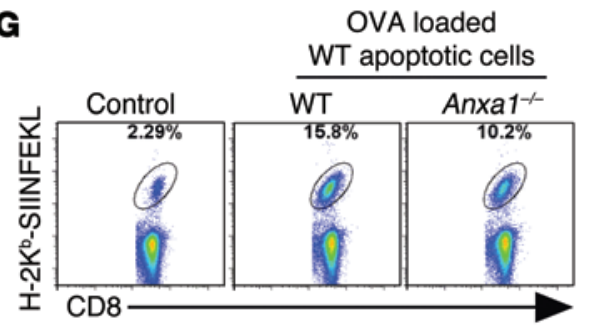

H

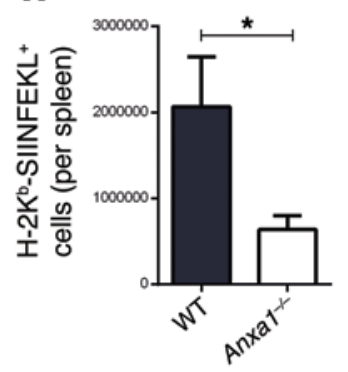

I No vesc WT vesc

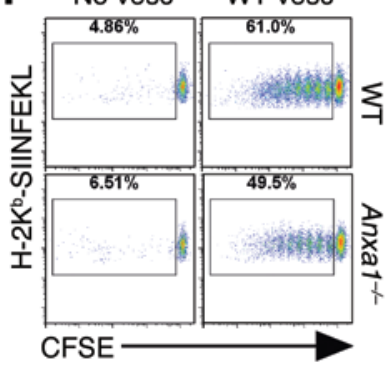

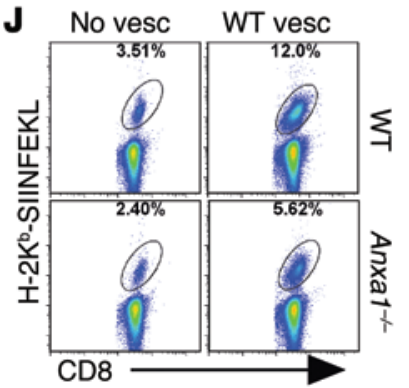

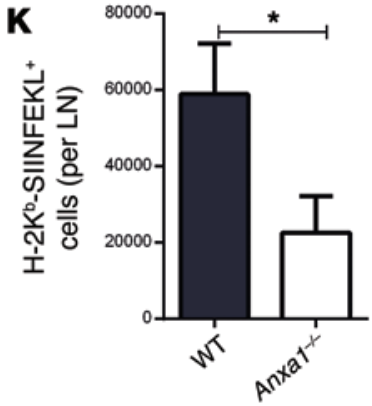

Figure 6. Annexin1 regulates cross-priming in DCs. (A and B) BMDCWT and DC ${ }^{A n x a-1--}$ were infected with BCG-OVA (MOI $\left.~ 2\right)$. After 4 hours of infection, CFSElabeled purified OT-I CD8 ${ }^{+} \mathrm{T}$ cells were added to the culture. At day $3, \mathrm{CD}^{+} \mathrm{T}$ cell proliferation was evaluated using CFSE dilution. Controls were CFSElabeled OT-I CD8 ${ }^{+} T$ cells cultured with DC without BCG-OVA infection. Each symbol represents 1 replicate (B). Results are representative of 6 independent experiments. ${ }^{*} P<0.05$ ( $t$ test). (C and D) CFSE-labeled, purified OT-I CD8 ${ }^{+} T$ cells were adoptively transferred to WT mice (i.v.). The following day, BCGOVA-infected DCWT and DC Anxa1-/- were transferred into the footpads of WT mice ( $n=3 /$ group). (D) Percentage of proliferation of SIINFEKL-specific CD8 ${ }^{+} T$

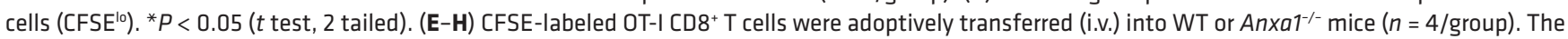
following day, mice were injected (i.v.) with WT apoptotic cells. At day 3 , T cell proliferation (E and F), frequency (G), and total number (H) of SIINFEKLspecific CD8 ${ }^{+} T$ cells were assessed in spleens. ${ }^{*} P<0.05$; ${ }^{*} P<0.01$ ( $t$ test). (I-K) CFSE-labeled OT-I CD8 ${ }^{+} T$ cells were adoptively transferred (i.v.) to WT or Anxa1 $1^{-1-}$ mice. The following day, mice were injected (i.v.) with WT vesicles ( $n=3 /$ group). At day $4, T$ cell proliferation (I), frequency, $(\mathrm{J})$ and total number (K) of SIINFEKL-specific CD8 ${ }^{+}$T cells were evaluated in popLN. ${ }^{*} P<0.05$ ( $t$ test). Numbers above outlined areas ( $\mathbf{A}$ and $\mathbf{I}$ ) indicate the percentage of $\mathrm{T}$ cell proliferation $\left(\mathrm{CFSE}^{\circ}\right)$. Numbers above bracketed lines $(\mathbf{E})$ indicate the percentage of cells that had undergone 3 or more divisions (left) or fewer than 3 divisions (right). Numbers above outlined areas (G and J) indicate the percentage of CD8+ $\mathrm{T}$ cells stained with H-2K ${ }^{\mathrm{b}}-\mathrm{SIINFEKL.}$

to detect nuclei and F-actin, respectively, and subjected to confocal microscopy. The uptake of WT vesicles $(\sim 80 \%)$ was significantly higher than that of Anxa1-/ vesicles ( 20\%) by DC ${ }^{\mathrm{WT}}$ (Figure 5, $\mathrm{A}$ and $\mathrm{B})$. Colocalization of $\mathrm{F}$-actin with the vesicles indicated that WT vesicles were confined to the cytosol (Figure 5A). Additionally, the fluorescence intensity ratio of cytosolic vesicles relative to cell nuclei, a quantitative analysis of cellular uptake, was also significantly increased using WT vesicles compared with Anxa1 ${ }^{-1-}$ vesicles (Supplemental Figure $4 \mathrm{H}$ ).

We next assessed the requirement of annexin1 for an optimal DC efferocytosis in vivo. WT or Anxa1 $1 /$ vesicles labeled with
PKH26 were injected into the footpads of WT mice. Twentyfour hours later, the uptake of PKH26+ apoptotic vesicles by DCs $\left(\mathrm{CD} 11 \mathrm{c}^{+} \mathrm{MHC}-\mathrm{II}^{\mathrm{hi}}\right)$ was evaluated in the draining popLN by confocal microscopy. At this time point, we found that the majority of the apoptotic vesicles localized to the interfollicular regions of the draining popLN in close association with $\mathrm{CD} 11 \mathrm{c}^{+}$and $\mathrm{CD} 8^{+} \mathrm{DCs}$ (Supplemental Figure 5B). Similar to the apoptotic cells shown in Figure 4, B and C, quantification by flow cytometry revealed that the frequency and total number of vesicle ${ }^{+} \mathrm{CD} 8^{+} \mathrm{DCs}$ from mice that received WT vesicles were significantly higher than from animals receiving Anxa1 ${ }^{--}$vesicles (Figure 5, C-E). Interest- 

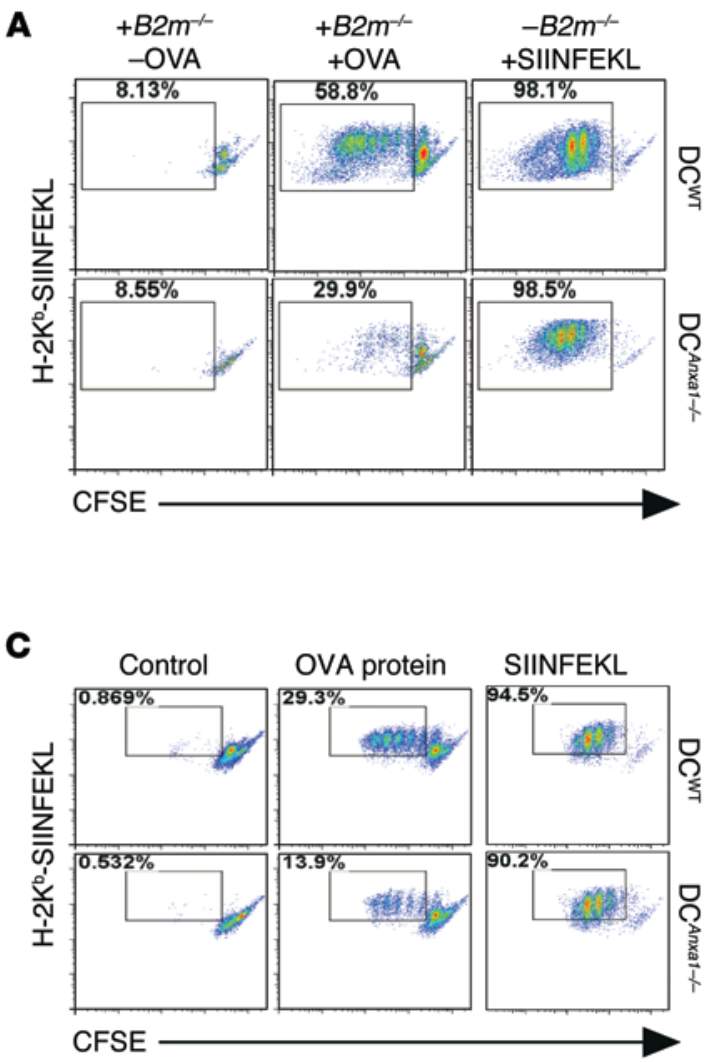

B

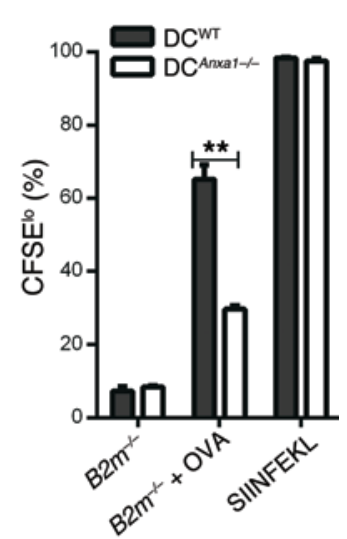

D

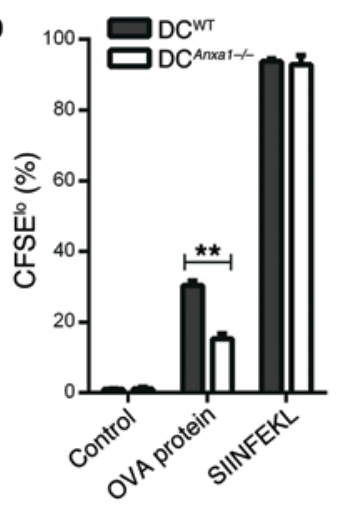

Figure 7. Annexin1 regulates cross-presentation in DCs. (A and B) DCs were purified from spleen and lymph nodes of WT or Anxa1 1 - mice, and cultured with irradiated $B 2 \mathrm{~m}^{-/-}$splenocytes, as indicated, that were either untreated $\left(+B 2 \mathrm{~m}^{-/-}-\mathrm{OVA}\right)$ or loaded with $10 \mathrm{mg} / \mathrm{ml}$ soluble OVA $\left(+B 2 \mathrm{~m}^{-/-}+\mathrm{OVA}\right)$. As a positive control, DCs were loaded with $1 \mu \mathrm{M}$ OVA peptide without $B 2 \mathrm{~m}^{-/-}$splenocytes $\left(-B 2 \mathrm{~m}^{-1-}\right.$ +SIINFEKL). CFSE-labeled OT-I CD8 ${ }^{+} \mathrm{T}$ cells were cultured with these cells, and T cell proliferation was determined by flow cytometry at day 3 . Numbers above gate $(\mathbf{A})$ indicate the percentage of CFSE ${ }^{10}$ cells. Results are representative of 2 independent experiments. ${ }^{* *} P<0.01$ ( $t$ test).

(C and D) DCs were purified from spleen and lymph nodes of WT or Anxa1 1 - mice and loaded with $2 \mu \mathrm{g} / \mathrm{ml}$ of OVA protein for 4 hours at $37^{\circ} \mathrm{C}$ or SIINFEKL. After washes, CFSE-labeled OT-I CD8 ${ }^{+} \mathrm{T}$ cells were cultured with these cells for 3 days and $T$ cell proliferation was determined by flow cytometry. Numbers above gate (C) indicate the percentage of CFSE ${ }^{10}$ cells. ${ }^{* *} P<0.01$ ( $t$ test). ingly, addition of recombinant annexin1 to $A n x a 1^{-/-}$vesicles prior to injection into the footpad of WT recipient mice increased the uptake of $A n x a 1^{-/-}$vesicles to a level similar to that observed with WT vesicles (Figure 5, C-E). Collectively, these in vitro and in vivo data suggest that expression of annexin1 on the surface of apoptotic cells and vesicles enhances efferocytosis by DCs.

To further investigate whether impairment in efferocytosis reduces cross-priming of $\mathrm{CD}^{+} \mathrm{T}$ cells in Anxa1 $1^{-/}$mice, we cocultured BMDCWT loaded with either WT or Anxa1 ${ }^{-1-}$ vesicles (generated upon BCG-OVA infection) and CFSE-labeled OT-I TCRtransgenic $\mathrm{CD}^{+} \mathrm{T}$ cells in vitro. Three days later, we assessed $\mathrm{CD} 8^{+}$ $\mathrm{T}$ cell proliferation. The percentage of divided OT-I cells (CFSE ${ }^{\mathrm{lo}}$ ) after cross-priming by DC ${ }^{\mathrm{WT}}$ loaded with WT vesicles was significantly higher than DC ${ }^{\mathrm{WT}}$ loaded with $A n x a 1^{-/-}$vesicles (Supplemental Figure 5C). To extend these findings to endogenous DCs, WT mice that received CFSE-labeled OT-I cells were administered apoptotic splenocytes loaded with OVA from WT or Anxa1 $1^{-/-}$mice the following day. Three days after injection of apoptotic cells, the proliferation of donor $\mathrm{CD}^{+} \mathrm{T}$ cells was substantially decreased in mice that received Anxa1 $1^{-/-}$compared with WT apoptotic cells (data not shown). Consistent with the reduced proliferation, $\mathrm{CD}^{+} \mathrm{T}$ cell expansion was significantly decreased in the spleens of WT mice that received Anxa1 ${ }^{--}$apoptotic cells (Supplemental Figure 5D). Taken together, these results indicate that the presence of annexin1 on the surface of apoptotic cells or vesicles is required for an optimal CD8 ${ }^{+} \mathrm{T}$ cell response through DC-dependent cross-priming.

Annexin1-deficient DCs are impaired in cross-priming. Previous studies have shown that annexin1 positively regulates DC activa- tion and maturation (36). We next investigated whether annexin1 also has an intrinsic role in DC cross-priming of $\mathrm{CD}^{+} \mathrm{T}$ cells following mycobacterial infection. We infected $\mathrm{BMDC}^{\mathrm{WT}}$ or $\mathrm{DC}^{\text {Anxal }-/-}$ with BCG-OVA (MOI 2), cocultured them with CFSE-labeled OT-I T cells, and measured CD8 ${ }^{+} \mathrm{T}$ cell proliferation. $\mathrm{CD}^{+} \mathrm{T}$ cells primed by $\mathrm{DC}^{\text {Anxal-/- }}$ underwent less proliferation $\left(\mathrm{CFSE}^{\mathrm{lo}}\right)$ compared with cells primed by DCWT (Figure 6, A and B). This difference was not observed in BMDCs loaded with SIINFEKL peptide, in which antigen processing was bypassed (Supplemental Figure $6 \mathrm{~A})$. To test whether the presence of annexin1 in DCs is required for an optimal $\mathrm{T}$ cell response in vivo, we adoptively transferred (i.v.) CFSE-labeled OT-I T cells to WT mice, followed by transfer

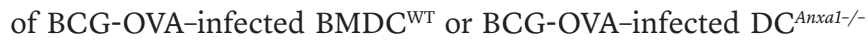
(footpad) 24 hours later (Figure 6C). Five days after adoptive transfer of DCs, we found that the proliferation of $\mathrm{CD}^{+} \mathrm{T}$ cells was significantly decreased in the draining popLN of WT mice that received BCG-OVA-infected $\mathrm{DC}^{\text {Anxal-/- }}$ compared with those that received infected $\mathrm{DC}^{\mathrm{WT}}$ (Figure $6 \mathrm{D}$ ).

To further evaluate the intrinsic role of annexin1 in DC crosspriming in vivo, WT or Anxa1 ${ }^{-/-}$mice that received CFSE-labeled OT-I T cells were administered OVA-loaded apoptotic cells from WT mice 24 hours later. The frequency of $\mathrm{CD} 8^{+} \mathrm{T}$ cell proliferation was significantly reduced in the spleen of recipient Anxa1 $1^{-/-}$ mice compared with WT controls (Figure 6, E and F). The reduced proliferation correlated with decreased frequency (Figure 6G) and total number (Figure 6H) of OT-I T cells observed in Anxa1 ${ }^{-1-}$ mice. The decreased $\mathrm{T}$ cell response detected in Anxa1 ${ }^{-/-}$mice was not due to impaired efferocytosis because the frequency and total 
A

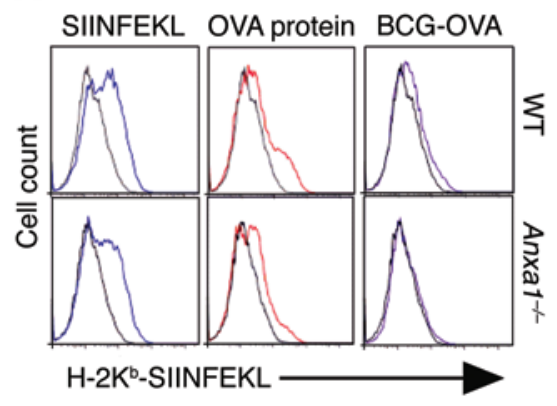

E

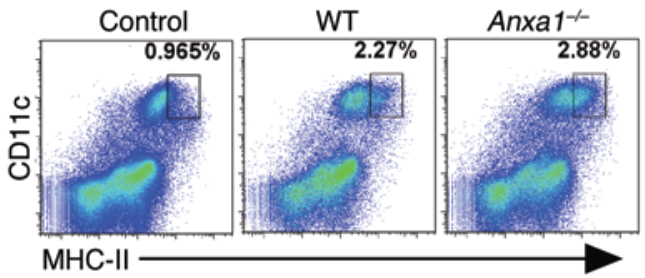

B

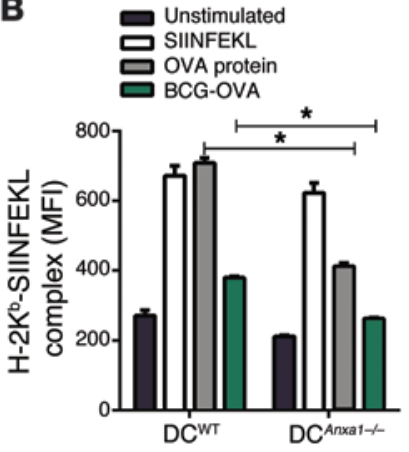

$\mathbf{F}$
C

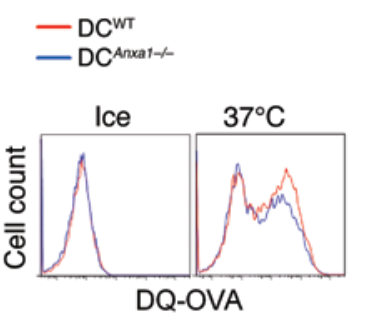

D

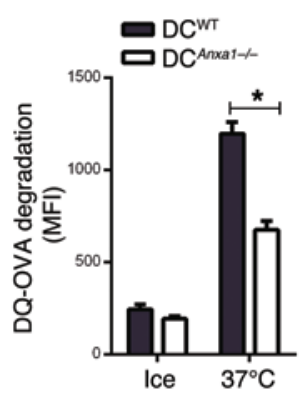

Figure 8. Reduced expression of MHC-I/peptide complex and antigen processing by Anxa1-/- DCs. (A and B) BMDCWT and DC ${ }^{\text {Anxa1-/- }}$ were incubated with $10 \mathrm{mg} / \mathrm{ml}$ of OVA protein or $10^{-5} \mu \mathrm{M}$ SIINFEKL or infected in vitro with BCG-OVA (MOI 10). After 16 hours, expression of H-2K ${ }^{\mathrm{b}}-\mathrm{SIINFEKL} \mathrm{complex} \mathrm{was} \mathrm{mea-}$ sured on the cell surface. (A) Histogram of stimulated cells (SIINFEKL, blue; OVA protein, red; BCG-OVA, purple) versus unstimulated cells (black). (B) MFI of expression of $\mathrm{H}-2 \mathrm{~K}^{\mathrm{b}}-\mathrm{SIINFEKL}$ complex on the surface of $D C^{\mathrm{WT}}$ and $D C^{A n \times a 1-1}$. Results are representative of 3 independent experiments. ${ }^{*} P<0.05(1-$ way ANOVA). (C and D) $10^{5}$ BMDCs were loaded with $15 \mu \mathrm{g} / \mathrm{ml}$ of a quenched OVA protein (DQ-OVA). Antigen processing was quantified as increase in MFI after 30 minutes. Controls were cells loaded with DQ-OVA for 15 minutes on ice. Results are representative of 3 to 6 independent experiments. ${ }^{*} P<0.05$ ( $t$ test, 1 tailed). (E-C) $20 \mu \mathrm{g}$ of DQ-OVA were injected (intranasal) into WT and Anxa1 1/- mice. Two hours later, lung cells were stained for DCs (CD11c $\mathrm{C}^{+} \mathrm{MHC}-\mathrm{II}^{\mathrm{h}}$ ) (E), and degradation of DQ-OVA was evaluated on this cell population as increase in MFI (F and $\mathbf{G})$. Numbers above outlined areas $(\mathbf{E})$ indicate the percentage of CD11 $\mathrm{C}^{+} \mathrm{MHC}-\mathrm{II}^{\mathrm{hi}}$ cells. Results are representative of 2 independent experiments. ${ }^{*} P<0.05$ ( $t$ test).

number of DCs containing $\mathrm{CFSE}^{+}$apoptotic cells in the spleen of WT and Anxa1 ${ }^{-/}$mice were similar (Supplemental Figure 6, $\mathrm{B}-\mathrm{D})$. A similar defect in antigen-specific $\mathrm{T}$ cell proliferation was observed in the popLN of Anxa1-/ mice when apoptotic vesicles were administered (footpad) in place of whole apoptotic cells (Figure 6, I-K). Collectively, these results indicate that the presence of annexin1 in DCs is required for an optimal cross-priming for $\mathrm{CD} 8^{+} \mathrm{T}$ cell proliferation.

Annexin1-deficient DCs are impaired in cross-presentation. We next determined the mechanism by which annexin1 affects the DC's ability to activate T cells. We initially evaluated whether the impaired $\mathrm{CD}^{+} \mathrm{T}$ cell response observed in Anxa1 $1^{--}$mice upon $\mathrm{Mtb}$ infection is due to an impaired migratory capacity of $\mathrm{DC}^{\text {Anxal- } /-}$ to the draining lymph nodes. To address this issue, WT and Anxa1 $1^{-1-}$ mice were intranasally injected with LPS or PBS, and DC migration to the lung-draining lymph nodes was evaluated 1 day later. We did not observe a significant difference in the frequency (Supplemental Figure 6E) or total cell number (Supplemental Figure 6G) of DCs (CD11 ${ }^{+}$MHC-II $\left.{ }^{\text {hi }}\right)$ in the lung-draining lymph nodes of WT and Anxa1 $1-$ mice injected with LPS. Similarly, the frequency (Supplemental Figure 6F) and total cell number of $\mathrm{CD}_{103^{+}}$DCs and CD11 $\mathrm{b}^{+}$DCs were not altered (Supplemental Figure 6, $\mathrm{H}$ and I). We next evaluated DC maturation upon BCG-OVA infection. $\mathrm{BMDC}^{\mathrm{WT}}$ or $\mathrm{DC}^{\mathrm{Anxal}-/}$ infected with BCG-OVA similarly upregulated the expression of CD40, CD80, MHC-II, and MHC-I (Supplemental Figures 6, J-N). Flower's group previously showed (37) that, in some tissues, the disruption of the annexin1 gene affected the expression of other annexins as well as genes involved in the eicosanoid pathways. As lipids from eicosanoid pathways play an important role in immunity to $M t b(15,16,38)$, we next investigated whether the absence of annexin1 in DCs affects the expression of other annexin family members (annexin2, $-4,-6$, and -10), cPLA2, sPLA2, mPGES1, 5LO, and NOS2 between BCG-infected $\mathrm{DC}^{\mathrm{WT}}$ and $\mathrm{DC}^{\text {Anxal- }}$. Annexin1 expression was downregulated upon BGC-OVA infection, but no significant differences in expression of the other genes were observed (Supplemental Figure 7A). Similarly, there was no difference in the production of PGE2 and LXA4, respective products of mPGES1 and 5LO enzyme activity (Supplemental Figure 7B).

To study the role of annexin1 in MHC-I-restricted crosspresentation of cell-associated antigen, purified splenic $\mathrm{DC}^{\mathrm{WT}}$ or $\mathrm{DC}^{\text {Anxal- } /-}$ were incubated with either OVA-loaded or unloaded apoptotic cells from $\beta 2$-microglobulin deficient mice $\left({\left.\mathrm{B} 2 \mathrm{~m}^{-/}\right)}^{-1}\right.$ and cocultured with CFSE-labeled OT-I T cells (39). As $\beta 2$-microglobulin-deficient cells are not able to directly activate $\mathrm{CD}^{+} \mathrm{T}$ cells, $\mathrm{DC}^{\mathrm{WT}}$ or $\mathrm{DC}^{\text {Anxal-/ }}$ can only present antigens to $\mathrm{CD} 8^{+}$ $\mathrm{T}$ cells via cross-presentation. $\mathrm{DC}^{\mathrm{WT}}$ or $\mathrm{DC}^{\text {Anxal- } /-}$ were loaded with SIINFEKL peptide as a positive control. Three days after coculture, we observed reduced proliferation of SIINFEKL-specific $\mathrm{CD}^{+} \mathrm{T}$ cells cross-primed by DC ${ }^{\text {Anxal- }- \text { - compared with DC }}{ }^{\mathrm{WT}}$ (Figure 7, A and B). In contrast, there was no difference in $\mathrm{CD}^{+} \mathrm{T}$ cell proliferation primed by SIINFEKL-loaded $\mathrm{DC}^{\mathrm{WT}}$ and $\mathrm{DC}^{\text {Anxal }-}-$. To 
A
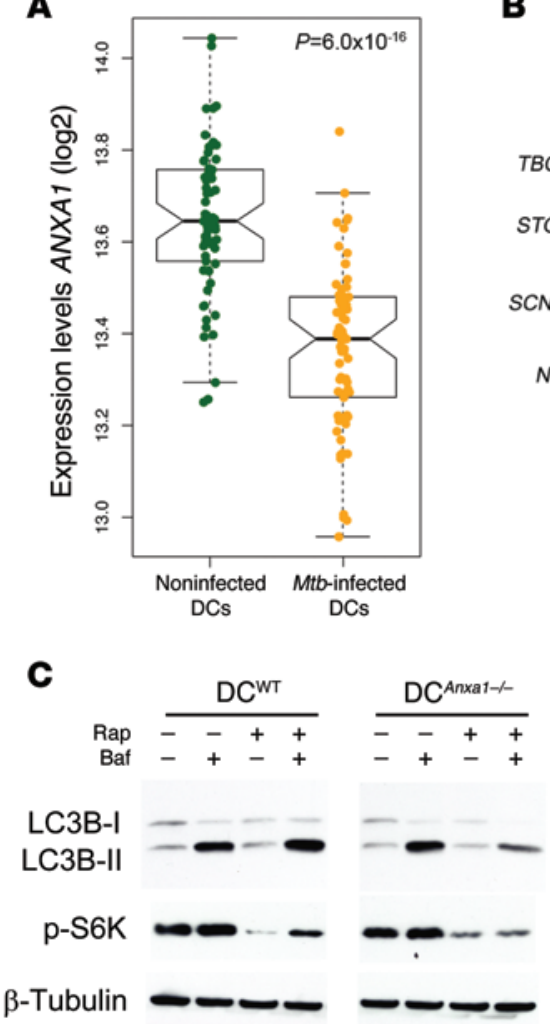

B
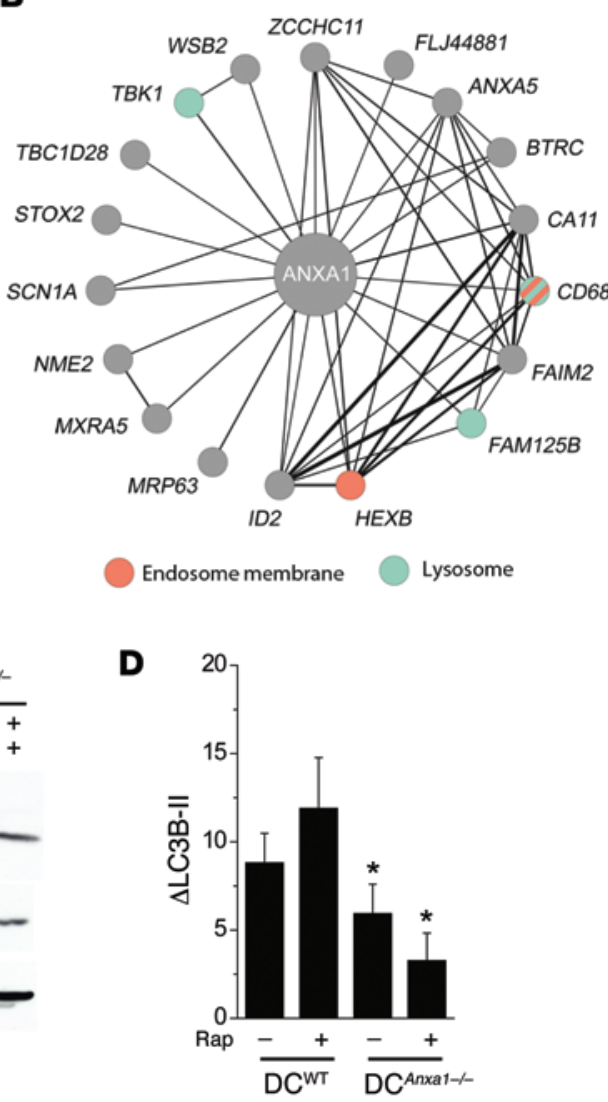

Figure 9. Mtb downregulates ANXA1 in human blood monocyte-derived DCs. (A) Box plots showing $\log _{2}$ expression levels of ANXA1 ( $y$ axis) in noninfected and $M t b$-infected DCs. (B) Gene regulatory network of ANXA1-associated genes. We identified 18 genes for which expression levels were significantly associated with the levels of ANXA1 in Mtb-infected DCs. The thickness of the edges connecting the nodes in the network (i.e., genes) reflects the strength of the association of these genes with ANXA1 as well as among themselves. Only connections with an $r^{2}$ value above 0.2 are shown. Genes associated with the endosome membrane and the lysosome pathways are highlighted. (C and D) Annexin1 mediates autophagy in $D C s$. (C) $D C^{W T}$ or $D C^{A n \times a 1-/-}$ were cultured with vehicle or the mTOR inhibitor rapamycin for 6 hours. Bafilomycin A1 was added 2 hours prior to cell lysis and Western blots for LC3B, phospho-S6 (pS6), and $\beta$-tubulin. (D) The means of bafilomycin-induced fold increase in LC3B-II levels \pm SEM $(\triangle \mathrm{LC} B \mathrm{BI})$, each obtained from 6 individual experiments. ${ }^{*} P<0.05$, KO vs. WT ( $t$ test). study the MHC-I-restricted cross-presentation of soluble antigen, purified endogenous DC ${ }^{\mathrm{WT}}$ or DC $\mathrm{DC}^{\text {Anxal-/- }}$ was incubated with soluble OVA protein and cocultured with CFSE-labeled OT-I T cells. Similar to cross-presentation of cell-associated antigen shown in Figure 7, A and B, OT-I T cells exhibited reduced proliferation when cross-primed by DC $\mathrm{C}^{\text {Anxal-/- }}$ compared with DC ${ }^{\mathrm{WT}}$. However, there was no difference in the proliferation of $\mathrm{CD} 8^{+} \mathrm{T}$ cells primed by SIINFEKL-loaded DC ${ }^{\mathrm{WT}}$ and DC $\mathrm{DC}^{\text {Anxal-/- }}$ (Figure 7, C and D).

To further evaluate cross-presentation, we measured the expression of MHC-I/OVA peptide (SIINFEKL) complex on the surface of BMDC ${ }^{\text {WT }}$ and DC $^{\text {Anxal-/- }}$ after BCG-OVA infection or loading with soluble OVA protein or OVA peptide (SIINFEKL). $\mathrm{DC}^{\mathrm{WT}}$ presented higher levels of MHC-I/SIINFEKL complexes upon loading with OVA protein and infection with BCG-OVA than $\mathrm{DC}^{\text {Anxal-/- }}$ (Figure 8, A and B). In contrast, both groups presented similar levels of MHC-I/SIINFEKL complex when loaded with SIINFEKL. Considering the expression of MHC-I was not affected by annexin1 (Supplemental Figure 6, J-N) while the levels of MHC-I/SIINFEKL complex were reduced, this suggests that there is a defect in DC antigen processing. To test this possibility, we used DQ-OVA, a self-quenching conjugate designed specifically for the study of antigen processing. Upon proteolysis, highly fluorescent peptides were released from DQ-OVA and quantified by flow cytometry. After 30 minutes of incubation, DC ${ }^{\mathrm{WT}}$ processed

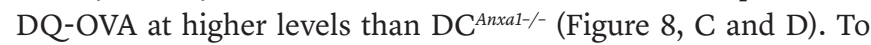
evaluate antigen processing by endogenous DCs, WT and Anxa1 $1^{-/}$ mice were intranasally injected with DQ-OVA. Similar to the in vitro data, we observed a higher degradation of DQ-OVA by DC ${ }^{\text {WT }}$ than by DC ${ }^{\text {Anxal-/- }}$ (Figure 8, E-G), indicating that annexin1 enhances antigen processing by DCs. Taken together, our results suggest that annexin1 is required for optimal cross-presentation by DC.

Mtb inhibits ANXA1 expression in human blood monocytederived DCs. We next investigated whether annexin1 (ANXA1 in humans) was differently expressed in human blood monocytederived DCs in response to $M t b$ infection. To do so, we interrogated transcript expression levels in human blood monocyte-derived DCs from 65 individuals, before and after 18-hour infection with $M t b$ (40). We found that ANXA1 was significantly downregulated in human blood monocyte-derived DCs in response to $M t b$ infection $\left(P=8.3 \times 10^{-16}\right.$; Figure $\left.9 \mathrm{~A}\right)$. To understand the effects of ANXA1 on broader $M t b$-mediated regulatory networks, we investigated the genome-wide relationships between interindividual variation in ANXA1 expression levels after $M t b$ infection and the expression levels of 12,957 other genes measured from the same individuals. We found that ANXA1 expression levels positively correlated with the expression of 18 other genes after correction for multiple testing $\left(P<1.6 \times 10^{-4}\right.$; FDR $<10 \%$; Figure 9B and Supplemental Table 1). Interestingly, the most enriched gene ontology terms and biological pathways among the ANXA1associated genes were related to the endosome and lysosome pathways (FDR < 5\%; Supplemental Table 2). Indeed, 4 of the 18 genes (22\%) associated with ANXA1 (Supplemental Figure 8) are known to be linked to the endosome membrane and/or to be involved in the lysosome pathway, significantly more than expected by chance $\left(P=8.1 \times 10^{-4}\right)$. Of particular note, TANK-binding kinase 1 (TBK1) was one of the most significant differentially 


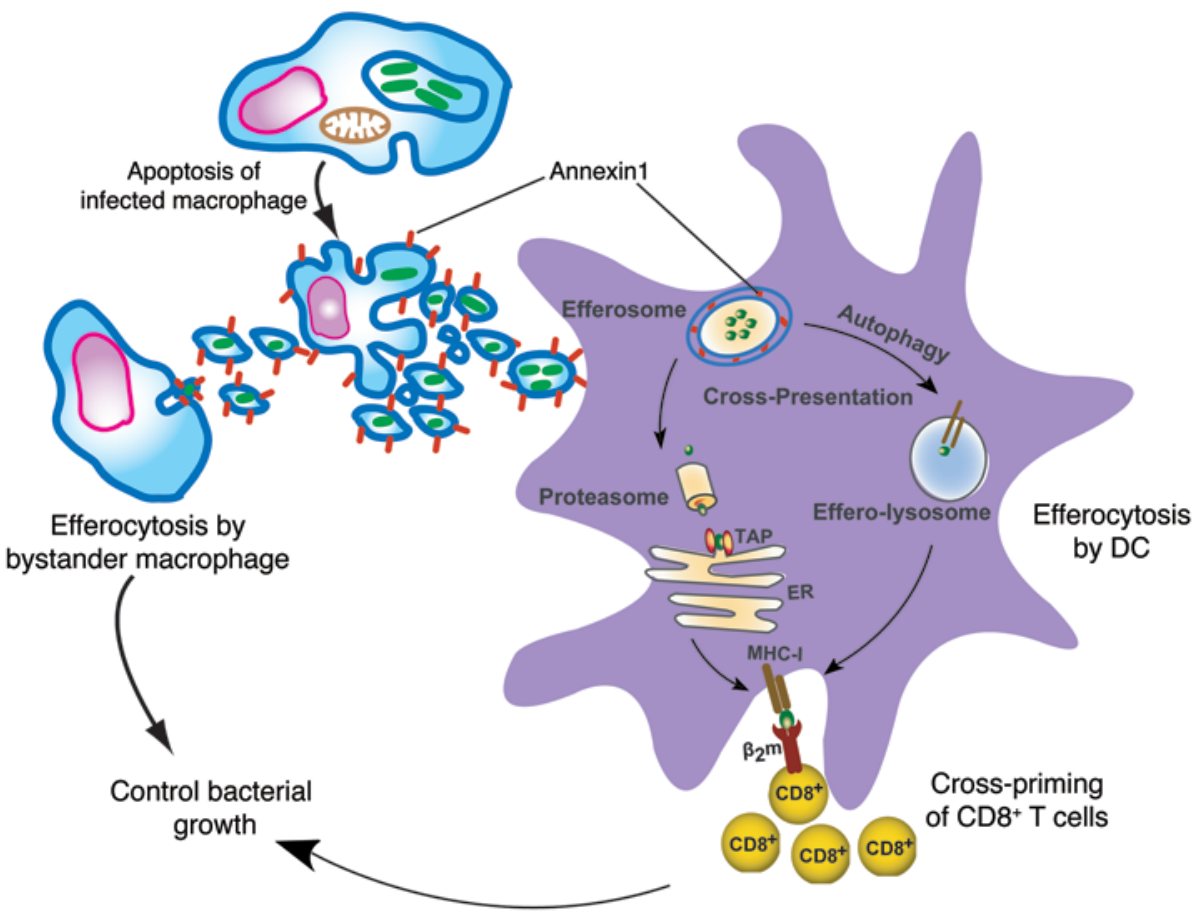

Figure 10. Regulatory role of annexin1 during Mtb infection. Mtb-infected macrophages undergoing apoptosis express annexin1 on the cell surface, which acts as an engulfment ligand. Bystander macrophages recognize this ligand and engulf apoptotic cells/vesicles containing live bacteria via efferocytosis to eliminate Mtb. Similarly, DCs recognize annexin1 and uptake apoptotic vesicles containing mycobacterial antigens. Mtb antigens are processed and loaded on MHC-I via crosspresentation. The presence of annexin1 on efferosomes, as well as in cytosol, may facilitate cross-presentation by increasing the availability of antigens in efferosomes to MHC-I, either via proteasome-ER-dependent pathway or/and vacular-dependent pathway (effero-lysosome). This will result in $\mathrm{CD}^{+} \mathrm{T}$ cell activation and expansion to control Mtb infection. expressed genes, with a $P$ value of $7.9 \times 10^{-6}$ (Supplemental Figure 8). It has been recently demonstrated that TBK1 is essential for the maturation of autophagic organelles into autolysosomes for the captured material degradation during $M t b$ infection (41). To establish the potential link between annexin1 and autophagy, we determined how the loss of annexin1 may affect autophagic flux. BMDC ${ }^{\mathrm{WT}}$ or $\mathrm{DC}^{\text {Anxal-/- }}$ were treated with vehicle or the mTOR inhibitor rapamycin, an inducer of autophagy initiation, for 6 hours, and the levels of lipidated LC3B (LC3B-II) were measured in the absence or presence of the lysosomal inhibitor bafilomycin A1. In DC ${ }^{\mathrm{WT}}$, rapamycin led to an increase in LC3B-II levels in cells exposed to bafilomycin (Figure 9C). In contrast, LC3B-II levels in DC $\mathrm{DC}^{\text {Anxal-/- }}$ exposed to bafilomycin were significantly reduced (Figure 9C). We next calculated the average bafilomycininduced change in LC3B-II expression (i.e., autophagic flux). Both basal and rapamycin-induced autophagic flux were significantly reduced in DC Anxal-/- $^{\text {compared with DC }}{ }^{\mathrm{WT}}$ (Figure 9D). Collectively, our results demonstrate that ANXA1 is downregulated in response to $M t b$ and that the regulatory network associated with ANXA1 is linked to the autophagy-dependent endosome/lysosome trafficking pathway, which is critical for cross-presentation.

\section{Discussion}

Apoptosis has evolved not only for the maintenance of tissue homeostasis, but also as a mechanism to transfer the essential immunological information that directly influences the outcome of immune responses. Accumulating studies suggest that apoptosis is critical for immune tolerance or activation. Although it has been shown that the uptake of apoptotic cells by phagocytes can be a source of antigens for immune tolerance or activation, our knowledge of the mechanism(s) involved in efferocytosis of apoptotic vesicles and their capacity in instructing immunity is limited. This is an important issue, considering that during the course of apoptosis, cells shed many vesicles that can be internalized by phagocytic cells. Thus, we hypothesized that efferocytosis of apoptotic vesicles is a critical mechanism for cross-presentation by DCs and protective immunity against $M t b$ infection, both of which depend on annexin1.

Annexin1 was initially discovered over 30 years ago as an antiinflammatory protein mimicking the effects of glucocorticoids $(42,43)$. Annexin1 inhibits PLA 2, COX-2, and iNOS expression and activates formyl peptide and lipoxin $\mathrm{A}_{4}$ receptors as well as inducing IL-10 and clearance of apoptotic cells (44). Such antiinflammatory effects of annexin1 have been shown to ameliorate diseases such as endotoxemia and peritonitis by suppressing leukocyte activation and transmigration $(45,46)$. Furthermore, it has been shown that activation of $\mathrm{T}$ cells leads to secretion of annexin1, which binds to its receptor (formyl peptide receptor [FPR]) in an autocrine/paracrine manner, promoting activation and differentiation of T cells. D'Acquisto and colleagues have shown that activation of naive $\mathrm{T}$ cells or Th1-polarized T cells in the presence of annexin1 promotes Th1-producing IL- 2 and IFN- $\gamma$ cells and dampens the Th2 phenotype $(28,29)$. These in vitro observations were further supported using a mouse model of rheumatoid arthritis, as annexin1 treatment exacerbated disease severity (28). Furthermore, the same group has demonstrated that annexin1-deficient mice showed an increased Th2 phenotype in a mouse model of allergic inflammation (29). Here, we have demonstrated that Anxa1-/- mice were highly susceptible to $M t b$ infection and that this was associated with decreased $M t b$-specific $\mathrm{CD} 8^{+} \mathrm{T}$ cell responses. By using a T cell-adoptive transfer model as well as generating chimeric annexin1-deficient T cells, we found, however, that annexin1 has no intrinsic role in the regulation of T cell immunity to $M t b$ infection. The disparate results between our group and others might reflect the immunogenic role of annexin1 in infection compared with its classical tolerogenic role in inflammatory diseases. 
Physiological apoptosis has an essential role in development, differentiation, and tissue homeostasis (47). Although the tolerogenic role of annexin1 in recognition and engulfment of apoptotic cells, which results in dampening of the immune response, has been well established (48), little is known about the immunogenic role of annexin1 during infectious diseases. It has only recently been accepted that apoptosis is an important host defense mechanism against microbial infections. Albert and colleagues initially demonstrated the importance of cross-priming through apoptotic cells in antiviral immunity $(8)$. Others $(11,12)$ as well as our group (14, 16) have previously shown that increased apoptosis in $M t b$-infected macrophages initiates an early cross-priming event that markedly enhances T cell-mediated immunity to infection. Activation of pattern recognition receptors, such as Toll-like receptors, can substantially differentiate immunogenic versus tolerogenic apoptosis (49), but the mechanism is still unknown. Winau and coworkers (12) initially demonstrated that generation of apoptotic vesicles from mycobacterial infected macrophages has the capability to crossprime $\mathrm{CD}^{+} \mathrm{T}$ cells. Our current study provides the mechanistic foundation for this observation by demonstrating that the presence of annexin1 on apoptotic vesicles was essential for transfer of antigens from apoptotic vesicles to DCs for cross-presentation and activation of $\mathrm{CD}^{+} \mathrm{T}$ cells. Furthermore, we have demonstrated that annexin1 plays an intrinsic role in autophagy and the antigenprocessing machinery of DCs, which enhances the efficiency of DCs in presenting antigens to $\mathrm{CD}^{+} \mathrm{T}$ cells. Accordingly, we also demonstrated that $M t b$ substantially suppresses annexin1 expression in human blood monocyte-derived DCs, highlighting the importance of annexin 1 in host immunity to $M t b$ infection. Thus, our results collectively indicate that annexin1 plays a critical role in immunity to $M t b$ infection by regulating efferocytosis as well as antigen cross-presentation by DCs.

Lung $\mathrm{CD}_{103}{ }^{+}$DCs and splenic $\mathrm{CD} 8^{+}$DCs have a greater ability to acquire and cross-present apoptotic cell-associated antigens in vivo than $\mathrm{CD} 11 \mathrm{~b}^{+}$DCs and CD8 ${ }^{-}$DCs, respectively $(34,50,51)$. Indeed, mice deficient in the transcription factor BATF3, which lack both $\mathrm{CD} 103^{+} \mathrm{CD} 11 \mathrm{~b}^{-}$DCs in the lungs and CD8 ${ }^{+} \mathrm{DCs}$ in the spleen, are defective in cross-presentation $(39,52)$. Corroborating our findings that annexin1 plays an intrinsic role for crosspresentation of apoptotic cells and vesicles in DCs, it has been demonstrated that both $\mathrm{CD} 8^{+} \mathrm{DCs}$ and $\mathrm{CD} 103^{+} \mathrm{DCs}$ express more annexin1 at the mRNA level than $\mathrm{CD}^{-}$DCs and $\mathrm{CD} 103^{-} \mathrm{CD} 11 \mathrm{~b}^{+}$ DCs, respectively (53).

The mechanisms by which antigens derived from efferocytosis are processed in DCs for cross-presentation are still poorly understood. Antigen cross-presentation is influenced by many factors, including efficiency of antigen capture, the biochemical nature of antigens, expression levels of MHC-I, and antigen processing. While here we have demonstrated that the presence of annexin 1 on the surface of apoptotic vesicles is required for optimal efferocytosis by DCs, we also have demonstrated an intrinsic role for annexin1 in antigen processing (Figure 10). There are 2 major intercellular pathways involved in cross-presentation of exogenous antigens: (a) the cytosolic pathway, in which antigens that are processed by the proteasome are loaded onto MHC-I via the ER or redirected to the phagosome containing MHC-I, and (b) the vacuolar pathway, in which exogenous antigens are directly degraded in the
MHC-I-containing phagosome followed by peptide loading onto MHC-I (6). However, after efferocytosis, this process may require additional receptors, as the efferosome contains an additional membrane distinct from the apoptotic vesicles. Thus, the presence of annexin 1 on apoptotic vesicles within the phagosome may also facilitate the access of antigens from phagosome to the intercellular pathways for cross-presentation. Additionally, we found that DCs either loaded with exogenous antigens (DQ-OVA) or infected with BCG-OVA required annexin1 for antigen processing.

Importantly, our observations that $M t b$ induced downregulation of annexin1 gene expression in human blood monocyte-derived DCs and that annexin1 regulates autophagy as well as the expression of genes such as TBK1 and FAM125B, which are involved in cytoplasmic cargo trafficking, reinforce the importance of annexin1 in antigen processing. It has been recently shown that both annexin1 (54) and TBK1 (41) are essential in autophagic maturation/degradation. Autophagy is a host-defense mechanism against mycobacterial infection $(55,56)$ that enhances peptide presentation by DCs (57). In the current study, we have also found that annexin1 regulates autophagy in DCs and that autophagy can serve as an effective system for the delivery of exogenous antigens in cross-presentation $(58,59)$. Furthermore, it has been shown that following efferocytosis, autophagy promotes apoptotic cell degradation (60). Thus, it is plausible that annexin1 may influence the cargo selection and access of antigens to either cytosolic or vacuolar pathways. Another possible explanation is that, upon antigen uptake, intracellular annexin1 colocalizes with early endosomes and also with phagosomal membrane $(61,62)$. As annexin1 has the ability to aggregate membranes in a calcium-dependent manner (63-65), annexin1 could facilitate the fusion of phagosome with lysosome. However, as $M t b$ is known to arrest phagosomal maturation, this pathway may be inhibited following infection. In contrast, if annexin1 also colocalizes with the surface of efferosome, this would lead to fusion with the lysosome and antigen degradation through the vacuolar pathway. Certainly, further experiments are needed to identify the molecular mechanisms involved in this process.

The high susceptibility of Anxa1 ${ }^{-/-}$mice to $M t b$ infection cannot only be explained by reduced $\mathrm{T}$ cell-mediated immunity. We anticipate that the lack of annexin1 on apoptotic cells/vesicles also markedly reduces efferocytosis by macrophages, further impairing innate immunity to $M t b$ infection (Figure 7). A recent study by Martin et al. elegantly demonstrated that efferocytosis is an essential antimycobacterial effector mechanism for controlling bacterial growth (17). In addition, deficiency of annexin1 in macrophages also impairs autophagic maturation (54), which is also important for control of mycobacterial growth $(55,56)$. This may explain why virulent $M t b$ specifically targets annexin 1 by removing its aminoterminal domain, resulting in a truncated nonfunctional protein (31). Although this study showed that annexin 1 is required for formation of apoptotic envelopes, our data indicate that annexin 1 does not affect the cell death program of macrophages infected with either virulent or avirulent strains of mycobacteria. These differences might be explained by the use of different experimental models and experimental methods used. Thus, further studies are necessary to precisely identify the role of annexin 1 in the cell death program.

Despite the worldwide application of BCG vaccination and other anti-Mtb interventions, $M t b$ remains one of the most successful 
human pathogens. Approximately 2 million people die of tuberculosis annually, and 8 to 10 million new cases of active tuberculosis occur each year due to the large reservoir of asymptomatic people chronically infected with $M t b$ (66). The success of this pathogen, which is transmitted person to person by the aerosol route, is closely linked to its ability to subvert both innate and adaptive immune responses. Thus, by targeting annexin1 and paralyzing efferocytosis, $M t b$ compromises an essential innate host defense mechanism as well as DC-mediated T cell immunity via cross-presentation. Given the potential importance of efferocytosis in effective innate and adaptive immunity to $M t b$ infection as well as an important role for annexin 1 in facilitating antigen delivery to DCs, synthetic nanoscale particles embedded with annexin 1 may provide an effective delivery system for vaccination against $M t b$.

\section{Methods}

Mice. Six- to ten-week-old C57BL/6, Rag1 ${ }^{-/-}$(Jax: 002216), Tcra $^{-/-}$(Jax: 002116), or B2 $\mathrm{m}^{-/}$(Jax: 002087) mice were from Jackson Laboratories. OT-I T cell antigen receptor-transgenic mice (specific for the OVA 257-264, peptide SIINFEKL, restricted by $\mathrm{H}-2 \mathrm{~K}^{\mathrm{b}}$ ) were from Taconic Farm (4175-M). Annexin1-deficient mice $\left(\right.$ Anxa1 $\left.^{-/}\right)$were obtained from Roderick Flower (William Harvey Research Institute, Barts and The London School of Medicine, London, United Kingdom) and were bred at McGill University; see Supplemental Methods.

Bacteria strains and infection. The virulent $M t b$ strain H37Rv, the attenuated strain H37Ra, and recombinant BCG-OVA were grown at $37^{\circ} \mathrm{C}$ under constant shaking in $7 \mathrm{H} 9$ medium (BD Biosciences) containing 0.2\% glycerol (Fisher), 0.05\% Tween 80 (Sigma-Aldrich), and $10 \%$ albumin-dextrose-catalase (BD Biosciences). In the case of BCGOVA, the medium was also supplemented with $50 \mu \mathrm{g} / \mathrm{ml}$ of kanamycin (Invitrogen). CFU were determined by plating serial dilutions in PBS-Tween 80 (0.05\% Tween 80$)$ on Middlebrook 7H10 medium (BD Biosciences) containing 0.5\% glycerol (Fisher), 10\% oleic acidalbumin-dextrose catalase (Sigma-Aldrich), and PANTA (BD Biosciences). Colonies were counted after 21 days.

For pulmonary infection, 100 bacteria of the $M t b$ strain H37Rv were delivered via the aerosol route using a nose-only exposure unit (Intox Products), and adequacy of infection was ascertained by enumeration of bacteria from the lungs of 2 animals 24 hours after infection. For i.v. infection, $10^{6}$ or $10^{8} \mathrm{H} 37 \mathrm{Rv}$ bacteria were resuspended in $200 \mu \mathrm{l}$ of PBS-Tween 80 (0.05\% Tween 80$)$ and delivered via the retroorbital vein; see Supplemental Methods.

Generation of BMDCs and BMDMs. BM from femurs and tibiae was flushed with RPMI medium. For generation of BMDCs from WT and Anxa1 $1^{-/}$mice (DCWT and $\mathrm{DC}^{\text {Anxal-/- }}$, respectively), cells were seeded in BMDC medium (RPMI supplemented with 10\% FBS, 1\% L-glutamine, $1 \%$ NEAA nonessential amino acids, $1 \%$ sodium pyruvate and $0.35 \%$ B-mercaptoethanol) containing $20 \mathrm{ng} / \mathrm{ml}$ of GM-CSF (Cedarlane) in cell-culture Petri dishes. At days 3 and 6, half of the volume (5 ml) was replaced by fresh medium containing $20 \mathrm{ng} / \mathrm{ml} \mathrm{GM-CSF}$. At day 7 , $50 \%$ of the volume was removed and centrifuged at $300 \mathrm{~g}$ for $5 \mathrm{~min}$ utes. Cells were resuspended with the same volume of fresh medium containing $20 \mathrm{ng} / \mathrm{ml} \mathrm{GM-CSF}$ and added back in the Petri dishes. DCs were used at day 8 . Purity was usually between $70 \%$ and $75 \%$, as evaluated by flow cytometry; see Supplemental Methods.

For generation of BMDMs, cells were seeded in BMDM medium (RPMI supplemented with 10\% FBS, 2 mM L-glutamine, 1\% MEM,
1\% NEAA, $1 \mathrm{mM}$ sodium pyruvate, 2\% HEPES, $100 \mathrm{U} / \mathrm{ml}$ penicillin, and $100 \mu \mathrm{g} / \mathrm{ml}$ streptomycin - all from Gibco, Invitrogen) containing 30\% L929 supernatant in tissue culture flasks and were allowed to differentiate into macrophages for 7 days. At day 3, fresh medium containing L929 supernatant was added. Macrophages were used from day 7 onwards. Purity was usually higher than $99 \%$, as evaluated by flow cytometry; see Supplemental Methods.

Flow cytometry. Aliquots of cells $\left(2 \times 10^{6}\right)$ from single-cell suspension obtained from spleens, lymph nodes, or collagenase-digested lungs and also BMDCs and BMDMs were first incubated with anti$\mathrm{CD} 16 / 32$ in $0.5 \% \mathrm{BSA} / \mathrm{PBS}$ at $4^{\circ} \mathrm{C}$ to block nonspecific $\mathrm{Ab}$ interaction with Fc receptors. For evaluation of Mtb32-specific $\mathrm{CD} 8^{+} \mathrm{T}$ cells, cells were then stained with $\mathrm{H}-2 \mathrm{D}^{\mathrm{b}}-\mathrm{Mtb} 32$ 309-318 tetramer PE (diluted 1:600, NIH Tetramer Core Facility, Emory University Vaccine Center, Atlanta, Georgia, USA), anti-CD8 PercP (53-6.7), anti-CD19 FITC (1D3), and anti-CD4 PE-Cy7 (RM4-5) for 30 minutes at $4^{\circ} \mathrm{C}$. After 2 washes with $0.5 \% \mathrm{BSA} / \mathrm{PBS}$, cells were fixed with $1 \%$ paraformaldehyde and kept at $4^{\circ} \mathrm{C}$ until acquisition. For SIINFEKL-specific CD ${ }^{+}$ $\mathrm{T}$ cell evaluation, cells were stained with $\mathrm{H}-2 \mathrm{~K}^{\mathrm{b}}$-SIINFEKL APC (ProImmune) in $0.5 \% \mathrm{BSA} / \mathrm{PBS}$ at room temperature. After 10 minutes incubation, cells were washed and stained with CD8 PercP for $30 \mathrm{~min}$ utes at $4^{\circ} \mathrm{C}$. After 2 washes, cells were acquired in the same day. For evaluation of BMDCs and BMDMs, cells were stained with anti-CD11c APC-Cy7 (HL3), F4/80 PE-Cy7 (BM8, eBioscience), anti-MHC-II PE (M5/114.15.2), anti-CD80 PercP-Cy5.5 (16-10A1), anti-CD86 FITC (GL1), and anti-CD40 APC (3/23) for 30 minutes at $4^{\circ} \mathrm{C}$. To measure expression of $\mathrm{H}-2 \mathrm{~K}^{\mathrm{b}}$-SIINFEKL complex on the surface of BMDCs, cells were stained with anti-H-2K ${ }^{\mathrm{b}}$-SIINFEKL PE (25D1.16, eBioscience) and anti-CD11c APC-Cy7 for 30 minutes at $4^{\circ} \mathrm{C}$. All antibodies were obtained from BD Biosciences. Acquisition was done in the LSRII flow cytometer (BD Biosciences) with FACSDiva Software version 6.1.2 (BD Biosciences) and analyses with FlowJo software (TreeStar).

In vivo cytotoxic assay. In vivo cytotoxic activity of antigen-specific $\mathrm{CD}^{+} \mathrm{T}$ cells was enumerated as previously described (67). Briefly, splenocytes of C57BL/6 mice were divided into 2 populations and labeled with the fluorogenic dye CFSE (Molecular Probes) at final concentrations of $5 \mu \mathrm{M}\left(\mathrm{CFSE}^{\mathrm{hi}}\right)$ or $0.5 \mu \mathrm{M}\left(\mathrm{CFSE}^{\mathrm{l}}\right)$. $\mathrm{CFSE}^{\text {hi }}$ cells were pulsed with $10 \mu \mathrm{M}$ SIINFEKL peptide for 30 minutes at $37^{\circ} \mathrm{C}$. CFSE ${ }^{\text {lo }}$ cells remained unpulsed. Subsequently, $\mathrm{CFSE}^{\text {hi }}$ cells were washed and mixed with equal numbers of $\mathrm{CFSE}^{\text {lo }}$ cells before injecting (i.v.) $20 \times 10^{6}$ total cells per mouse. Recipient animals were mice that had been infected or not with BCG-OVA. Spleen cells of recipient mice were collected 20 hours after transfer and analyzed by FACS. Percentage of specific lysis was determined using the following formula: 1 - $\left(\left[\% \mathrm{CFSE}^{\mathrm{hi}}\right.\right.$ infected $/ \% \mathrm{CFSE}^{\text {lo }}$ infected] $/\left[\% \mathrm{CFSE}^{\text {hi }}\right.$ naive $/ \% \mathrm{CFSE}^{\text {lo }}$ naive $\left.]\right) \times 100 \%$.

Generation of mixed BM chimeric mice. BM from femurs and tibiae was flushed with RPMI medium. BM cells from Tcra-deficient mice and $A n x a 1^{-/-}$mice were mixed in a proportion of 4 to 1 , respectively. This mixture was used to generate $\mathrm{T}$ cell ${ }^{\text {Anxal-- }}$ chimeric mice. BM cells from Tcra-deficient mice and WT mice were combined in the same way to generate $\mathrm{T}$ cell ${ }^{\text {Anxal+/+ }}$ control mice. As recipient mice, we used Tcra-deficient mice that were irradiated with 9 Gy (2 times using $4.5 \mathrm{~Gy}$ with an interval of 3 hours). These mice were kept under antibiotic treatment (128 mg polymixin B and $1.1 \mathrm{~g}$ neomycin trisulfate [Sigma-Aldrich] per liter of drinking water) for 10 days after irradiation. Sixteen hours after irradiation, $4 \times 10^{6}$ mixed BM cells were i.v. transferred to recipient mice. Chimeric mice were used after 12 weeks, 
at which time the hematopoietic compartment was reconstituted as determined by flow cytometry; see Supplemental Methods.

Purification of apoptotic vesicles. For generation of apoptotic vesicles, BMDMs from WT and Anxa1 $1^{-/-}$mice were infected with $10 \mathrm{MOI}$ of BCG-OVA plus $10 \mu \mathrm{g} / \mathrm{ml}$ of OVA protein for 4 hours at $37^{\circ} \mathrm{C}$. After 2 washes, cells were kept in RPMI medium in the absence of FBS for 6 days. Deprivation of FBS induced apoptotic vesicles. After this period, supernatant of cell culture was collected. Following centrifugation to remove cellular debris $(800 \mathrm{~g}$ and $1800 \mathrm{~g}$ ), the remaining solution containing the apoptotic vesicles was filtered using 50-ml centrifugal filters with a 50-kDa molecular cut-off (Millipore Corp.). The resulting retentate containing the apoptotic vesicles was then collected in $1.5 \mathrm{ml}$ LoBind tubes (Eppendorf) for further characterization. Further characterization of apoptotic vesicles are described in Supplemental Methods.

Generation of apoptotic cells. For generation of apoptotic cells, WT and Anxa1 $1-$ splenocytes were osmotically shocked to accelerate apoptosis (34). Briefly, single-cell suspension of splenocytes was prepared in serum-free medium. $2.5 \times 10^{7}$ cells were incubated in $170 \mu \mathrm{l}$ hypertonic medium (0.5 M sucrose, $10 \% \mathrm{wt} /$ vol polyethylene glycol 1000, and $10 \mathrm{mM}$ HEPES in RPMI, pH 7.2) at $37^{\circ} \mathrm{C}$ for 10 minutes. $2.2 \mathrm{ml}$ of prewarmed hypotonic medium (60\% RPMI and $40 \% \mathrm{H}_{2} \mathrm{O}$ ) was added, followed by an additional 2 minutes of incubation at $37^{\circ} \mathrm{C}$. The cells were centrifuged, washed twice with cold PBS, and resuspended in RPMI supplemented with 10\% FBS. Cells were incubated for an extra 2 hours at $37^{\circ} \mathrm{C}$ before transference to mice. In some experiments, apoptotic cells were first labeled with $5 \mu \mathrm{M} \mathrm{CFSE}$ and then subjected to osmotic shock.

Efferocytosis assay. For in vitro efferocytosis assay, WT and Anxa1 ${ }^{-1-}$ vesicles were suspended to a concentration of $5 \mu \mathrm{g} / \mathrm{ml}$ of protein in serum-free RPMI 1640 medium. In order to later visualize uptake, the lipid bilayer of the apoptotic vesicles was stained using the PKH26 Kit (Sigma-Aldrich). Further purification of the apoptotic vesicles from excess stain was performed using $1.5 \mathrm{ml}$ centrifugal filtration tubes with 50-kDa molecular cut-off (Millipore). BMDCs from WT mice (DCWT) were loaded with WT and Anxa1 ${ }^{-/-}$vesicles for 30 minutes at $37^{\circ} \mathrm{C}$ to allow for sufficient uptake. Cells were then fixed with $10 \%$ formalin (Sigma-Aldrich), followed by permeabilization with $0.1 \%$ Triton X-100 (Invitrogen) and staining with Alexa Fluor 488-conjugated phalloidin and Hoechst 33342 (Molecular Probes) for F-actin and nuclei visualization, respectively. Confocal imaging was then performed using a Zeiss LSM 510 confocal microscope (Carl Zeiss). All images were acquired while maintaining a constant laser intensity and detector gain. Following image acquisition, the composite images were assembled using ImageJ software (NIH). The intensity of fluorescence was then evaluated for uptaken vesicles and cell nuclei using CellProfiler image analysis software (Broad Institute). The ratio of fluorescence intensity of uptaken vesicles relative to cell nuclei was then determined to give a quantitative analysis of cellular uptake.

In vivo efferocytosis assay was performed with CFSE-labeled apoptotic cells or PKH26-labeled vesicles. $2 \times 10^{7} \mathrm{CFSE}$-labeled WT or Anxa1 ${ }^{-1}$ apoptotic cells were generated as described above and transferred (i.v.) into WT mice or Anxa1 ${ }^{-1-}$ mice when indicated. One hour later, spleens of recipient mice were harvested and DCs were enriched by a positive selection for CD11c. Cells were stained with anti-CD11c APC (HL3), MHC-II V500 (M5/114.15.2), CD8 PercP, and CD19 V450 (1D3) (all antibodies from BD Biosciences). Cells positive for CFSE were considered to have engulfed injected apoptotic cells. Fifty micrograms of PKH26labeled WT or Anxa1 ${ }^{-/-}$vesicles were transferred into the footpads of WT mice. When indicated, $10 \mu \mathrm{g} / \mathrm{ml}$ of recombinant annexin1 (Cloud-Clone Corp.) was mixed with Anxa1 ${ }^{-/}$vesicles before injection into the footpad. Twenty-four hours later, draining popLNs were harvested and cells were stained with anti-CD11c APC, MHC-II V500, CD8 PercP, and CD11b APC-Cy7 (clone M1/70, no. 557657). Cells positive for PKH26 (PE) were considered to have engulfed injected apoptotic vesicles.

Confocal microscopy. Spleens or popLN were harvested and immediately frozen in optimal cutting temperature embedding compound over liquid nitrogen. Frozen tissues were cut into 6 - to 8 - $\mu \mathrm{m}$ sections using a cryostat (AO Scientific Instruments) and fixed in a mixture of ice-cold $75 \%$ acetone $/ 25 \%$ ethanol for 5 minutes. Sections were blocked in PBS plus $2 \%$ BSA for 60 minutes prior to specific antibody staining. Surface antibody staining included CD $8 \alpha$ (53-6.7; BD Biosciences), B220 (RA36B2), CD11c (N418; eBioscience), and SIGN-R1 (22D1; eBioscience) coupled with detection of CFSE-labeled apoptotic cells or PKH26labeled vesicles as described above. Stained sections were coverslipped using SHUR/Mount Liquid Mounting Medium (Triangle Biomedical). Image acquisition was performed using the FluoView 1000 confocal microscopy platform (Olympus) and analyzed using ImageJ.

DC enrichment and purification. Spleens and lymph nodes were used for endogenous DC analysis. Briefly, spleens were flushed with $100 \mathrm{mU} / \mathrm{ml}$ collagenase D (Roche), teased apart with fine forceps, and digested with $400 \mathrm{mU} / \mathrm{ml}$ collagenase $\mathrm{D}$ for 15 minutes at $37^{\circ} \mathrm{C}$ (68). After digestion, splenic and lymph node DCs were enriched by positive selection for CD11c (Miltenyi Biotec). DCs were enriched with 1 round of positive selection; the amount of DCs in the cell population was approximately $30 \%$. Purified DCs were subjected to 2 or more rounds of positive selection; the amount of DCs in the cell population was between $75 \%$ and $80 \%$.

Antigen presentation assays. For in vitro cross-priming assay, BMDCs were generated as described above. $10^{5}$ BMDCs were incubated with $1 \mathrm{mg} / \mathrm{ml}$ of apoptotic vesicles or infected with BCG-OVA (MOI $\sim$ ) for 4 hours at $37^{\circ} \mathrm{C}$. OVA peptide (SIINFEKL) $\left(10^{-5}\right.$ and $10^{-6}$ $\mu \mathrm{M})$ was used as positive control. After washes, $10^{5} \mathrm{CFSE}$-labeled OT-I TCR-transgenic $\mathrm{CD}^{+} \mathrm{T}$ cells were added per well. $\mathrm{CD} 8^{+} \mathrm{T}$ cells were purified by negative selection (Stem Cell Technologies) and labeled with $5 \mu \mathrm{M}$ CFSE. After 3 days of coculture, cells were harvested and stained with anti-CD8 PercP in PBS containing 0.5\% BSA; CD8 ${ }^{+} \mathrm{T}$ cell proliferation was measured by reduction in CFSE expression $\left(\mathrm{CFSE}^{\mathrm{lo}}\right)$ on the $\mathrm{CD}^{+} \mathrm{T}$ cell (PercP-positive gate) population.

In vivo cross-priming assay was performed using OVA osmotically loaded apoptotic cells or apoptotic vesicles. WT or Anxa1 $1^{-/-}$mice were adoptively transferred (i.v.) with CFSE-labeled OT-I TCR-transgenic $\mathrm{CD}^{+} \mathrm{T}$ cells. On the following day, mice were injected i.v. or in footpads with $2 \times 10^{7}$ apoptotic cells (WT or Anxa1 $1^{-1-}$ when indicated) or $50 \mu \mathrm{g}$ apoptotic vesicles (WT or Anxa1 ${ }^{-/}$when indicated), respectively. Three days after injection, spleen or draining popLNs were harvested. Cells were stained with $\mathrm{H}-2 \mathrm{~K}^{\mathrm{b}}$-SIINFEKL APC, anti-CD8 PercP, and anti-CD19 V450. Proliferation of antigen-specific CD8 ${ }^{+} \mathrm{T}$ cells was measured by reduction in CFSE expression $\left(\mathrm{CFSE}^{\mathrm{lo}}\right)$ on the $\mathrm{H}-2 \mathrm{~K}^{\mathrm{b}}-$ SIINFEKL ${ }^{+} \mathrm{CD} 8^{+} \mathrm{T}$ cell population.

In vitro cross-presentation assay of cell-associated antigen was performed as described by Hildner et al. (39). Briefly, single-cell suspensions of spleens from $\beta 2$-microglobulin-deficient mice were prepared in serum-free medium. Cells were loaded with OVA by osmotic shock. Incubation with hypertonic medium occurred in the presence or absence of $10 \mathrm{mg} / \mathrm{ml}$ OVA. After addition of hypotonic medium 
and washes with cold PBS, cells were incubated for 1 hour at $37^{\circ} \mathrm{C}$ followed by irradiation (13.5 Gy). $10^{5}$ purified WT or Anxa1 $1^{-/}$DCs were incubated with $5 \times 10^{5}$ splenic cells that were either untreated $\left(+B 2 \mathrm{~m}^{-/}\right.$ -OVA) or loaded with OVA $\left(+B 2 m^{-/}+\mathrm{OVA}\right)$ and cocultured with CFSElabeled OT-I TCR-transgenic CD8 ${ }^{+} \mathrm{T}$ cells. As a positive control, purified DCs were loaded with $1 \mu \mathrm{M}$ SIINFEKL. After 3 days, cells were stained with $\mathrm{H}-2 \mathrm{~K}^{\mathrm{b}}-\mathrm{SIINFEKL} \mathrm{APC}$ and anti-CD8 PercP. Proliferation of antigen-specific $\mathrm{CD} 8^{+} \mathrm{T}$ cells was measured by reduction in CFSE expression $\left(\mathrm{CFSE}^{\mathrm{lo}}\right)$ on the $\mathrm{H}-2 \mathrm{~K}^{\mathrm{b}}-\mathrm{SIINFEKL}{ }^{+} \mathrm{CD}^{+} \mathrm{T}$ cell populations.

For cross-presentation assay with soluble antigen, purified DCs from spleen and lymph nodes of WT and $A n x a 1^{-/-}$mice were incubated with $2 \mu \mathrm{g} / \mathrm{ml}$ OVA protein (Sigma-Aldrich) for 4 hours at $37^{\circ} \mathrm{C}$. Positive control cells were incubated with $1 \mu \mathrm{M}$ SIINFEKL. After washes, cells were cocultured with CFSE-labeled OT-I TCR-transgenic CD8 ${ }^{+}$ $\mathrm{T}$ cells. After 3 days, cells were stained with $\mathrm{H}-2 \mathrm{~K}^{\mathrm{b}}-\mathrm{SIINFEKL}$ APC and anti-CD8 PercP. Proliferation of antigen-specific $\mathrm{CD} 8^{+} \mathrm{T}$ cells was measured by reduction in CFSE expression $\left(\mathrm{CFSE}^{\mathrm{lo}}\right)$ on the $\mathrm{H}-2 \mathrm{~K}^{\mathrm{b}}$ SIINFEKL ${ }^{+} \mathrm{CD}^{+} \mathrm{T}$ cell population.

Antigen-processing assay. For in vitro antigen-processing assay, BMDCs were generated as described above. $10^{5}$ cells were loaded with $15 \mu \mathrm{g} / \mathrm{ml}$ of a quenched OVA protein (DQ-OVA, Molecular Probes). After 15 minutes of incubation at $37^{\circ} \mathrm{C}$ to allow antigen uptake, cells were washed twice with ice-cold PBS containing 5\% FBS at $4^{\circ} \mathrm{C}$. Then cells were resuspended in RPMI containing 10\% FBS and transferred to $37^{\circ} \mathrm{C}$. Processing of OVA into peptide was measured as increase in median fluorescence intensity (MFI) after 30 minutes. Controls were cells loaded with DQ-OVA for 15 minutes on ice. DQ-conjugated OVA peptide was quantified using the FITC channel. For in vivo antigenprocessing assay, $20 \mu \mathrm{g}$ of DQ-OVA was delivered intranasally into WT or Anxa1 $1^{-/}$mice. Approximately 2 hours later, lungs of recipient mice were harvested and cells were stained with anti-CD11c APC, MHC-II V500, and CD19 V450.

Isolation and infection of human monocyte-derived DCs. Blood samples were obtained from 65 healthy donors from Research Blood Components. Isolation and infection of DCs with $M t b$ (H37Rv) for 18 hours, RNA extraction, and quality verification have been previously described (40).

Genome-wide gene expression data in human DCs. Genome-wide gene expression profiling of untreated and infected DCs was obtained by hybridizing the RNA to the Illumina HumanHT-12 v4 Expression BeadChips arrays. The cDNA synthesis, labeling, and subsequent hybridization to the microarrays were performed by the Southern California Genotyping Consortium at UCLA. A detailed description of the quality control measures of the data can be found in Barreiro et al. (40). All original microarray data were deposited in the NCBI's Gene Expression Omnibus (GEO GSE3415). To test whether ANAX1 was differently expressed after $M t b$ infection, we used a linear modelingbased approach. Specifically, we used the Bioconductor limma package (69) to fit a linear model with individual treatment (i.e., $M t b$ infection) and batch as fixed effects. We included a batch effect because the RNA samples were hybridized in 2 separate batches. We subsequently used the empirical Bayes approach of Smyth (69) to calculate a moderated $t$ statistic and $P$ value. In order to find genes for which expression levels were robustly correlated with ANAX1, we calculated Pearson's correlation coefficients between the expression levels of ANAX1 in DCs from 65 individuals infected with $M t b$ and the expression levels of 12,957 other genes measured on the same samples. To correct for multiple testing, we used the $q$-value approach described by Storey et al. (70); see Supplemental Methods.

Western blot. For autophagy evaluation, BMDCs were generated as described above. Cells were treated with $250 \mathrm{nM}$ rapamycin for 6 hours and in the presence or absence of BAF-A1 $(250 \mathrm{nM})$ for the last 2 hours. After treatments, the cells were washed twice with ice-cold PBS and then collected in $100 \mu \mathrm{l}$ of ice-cold lysis buffer (50 mM Tris$\mathrm{HCl}$, pH 7.5, $150 \mathrm{mM} \mathrm{NaCl}, 1 \mathrm{mM}$ EDTA, $100 \mathrm{mM} \mathrm{NaF}, 1 \mathrm{mM} \mathrm{Na} \mathrm{VO}_{4}$, 1\% NP-40, 40 mM $\beta$-glycerophosphate, 10\% glycerol, $1 \mathrm{mM} \mathrm{PMSF}$, $10 \mu \mathrm{g} / \mathrm{ml}$ leupetin, and $10 \mu \mathrm{g} / \mathrm{ml}$ aprotinin). Twenty micrograms of protein were loaded onto SDS-15\% polyacrylamide gel. Proteins were transferred onto a polyvinylidene difluoride membrane, blocked with $5 \%$ milk, and probed with primary antibodies (anti-LC3B [Cell Signaling] and anti- $\beta$-tubulin [DSHB]), followed by treatment with a peroxidase-conjugated secondary antibody (Cell Signaling). The blots were further developed using a Pierce ECL Kit (Thermo Scientific) according to the manufacturer's instructions.

Statistics. Data are expressed as mean \pm SEM. Data were analyzed by 2-tailed Student's $t$ test or 1-way ANOVA as appropriate using the GraphPad Prism program (version 6). For survival analyses, log-rank test was performed. $P$ values of less than 0.05 were considered significant.

Study approval. All animal studies were conducted in accordance with the guidelines of and approved by the Animal Research Ethics Board of McGill University. Human blood samples were obtained from Research Blood Components. Signed, written consent was obtained from all individuals, in accordance with the company's independent ethics committee approval.

\section{Acknowledgments}

This work was supported by the Canadian Institute of Health Research (CIHR) operating grants (MOP-130310) and National Sciences and Engineering Research Council of Canada (NSERC) (G231908) to M. Divangahi. M. Divangahi also holds a CIHR New Investigator Award. M. Tabrizian's laboratory is supported by CIHRNanomedicine/Regenerative Medicine and Genome Quebec. We thank Roderick Flower (William Harvey Research Institute, Barts and The London School of Medicine) for providing Anxa1 $1^{-/-}$mice.

Address correspondence to: Maziar Divangahi, Assistant Professor of Medicine, Department of Microbiology and Immunology, McGill International TB Centre, McGill University, MeakinsChristie Laboratories, 3626 St. Urbain Street, Montreal, Quebec, H2X 2P2, Canada. Phone: 514.398.3864, ext. 089727; E-mail: maziar.divangahi@mcgill.ca.

Anthony Michel Jean Sanchez's present address is: University of Perpignan Via Domitia, Laboratoire Performance Santé Altitude, Font-Romeu, France.

\footnotetext{
1. Chen CY, et al. A critical role for CD8 T cells in a nonhuman primate model of tuberculosis. PLoS Pathog. 2009;5(4):e1000392.

2. Flynn JL, Goldstein MM, Triebold KJ, Koller B,
}

Bloom BR. Major histocompatibility complex class I-restricted $\mathrm{T}$ cells are required for resistance to Mycobacterium tuberculosis infection. Proc Natl Acad Sci U S A . 1992;89(24):12013-12017.
3. Woodworth JSM, Behar SM. Mycobacterium tuberculosis-specific $\mathrm{CD}^{+} \mathrm{T}$ cells and their role in immunity. Crit Rev Immunol. 2006;26(4):317-352. 4. Canaday DH, Ziebold C, Noss EH, Chervenak 
KA, Harding CV, Boom WH. Activation of human $\mathrm{CD}^{+} \alpha \beta \mathrm{TCR}^{+}$cells by Mycobacterium tuberculosis via an alternate class I MHC antigen-processing pathway. J Immunol. 1999;162(1):372-379.

5. Grotzke JE, Siler AC, Lewinsohn DA, Lewinsohn DM. Secreted immunodominant Mycobacterium tuberculosis antigens are processed by the cytosolic pathway. JImmunol. 2010;185(7):4336-4343.

6. Mantegazza AR, Magalhaes JG, Amigorena S, Marks MS. Presentation of phagocytosed antigens by MHC class I and II. Traffic C $p h$ Den. 2013;14(2):135-152.

7. Albert ML. Death-defying immunity: do apoptotic cells influence antigen processing and presentation? Nat Rev Immunol. 2004;4(3):223-231.

8. Albert ML, Sauter B, Bhardwaj N. Dendritic cells acquire antigen from apoptotic cells and induce class I-restricted CTLs. Nature. 1998;392(6671):86-89.

9. Bosnjak L, Miranda-Saksena M, Koelle DM, Boadle RA, Jones CA, Cunningham AL. Herpes simplex virus infection of human dendritic cells induces apoptosis and allows crosspresentation via uninfected dendritic cells. J Immunol. 2005;174(4):2220-2227.

10. Yrlid U, Wick MJ. Salmonella-induced apoptosis of infected macrophages results in presentation of a bacteria-encoded antigen after uptake by bystander dendritic cells. JExp Med. 2000;191(4):613-624.

11. Schaible UE, et al. Apoptosis facilitates antigen presentation to $\mathrm{T}$ lymphocytes through MHC-I and CD1 in tuberculosis. Nat Med. 2003;9(8):1039-1046.

12. Winau F, et al. Apoptotic vesicles crossprime CD8 $\mathrm{T}$ cells and protect against tuberculosis. Immunity. 2006;24(1):105-117.

13. Behar SM, Divangahi M, Remold HG. Evasion of innate immunity by Mycobacterium tuberculosis: is death an exit strategy? Nat Rev Microbiol. 2010;8(9):668-674

14. Behar SM, Martin CJ, Nunes-Alves C, Divangahi M, Remold HG. Lipids, apoptosis, and crosspresentation: links in the chain of host defense against Mycobacterium tuberculosis. Microbes Infect Inst Pasteur. 2011;13(8-9):749-756.

15. Divangahi M, et al. Mycobacterium tuberculosis evades macrophage defenses by inhibiting plasma membrane repair. Nat Immunol. 2009;10(8):899-906.

16. Divangahi M, Desjardins D, Nunes-Alves C, Remold HG, Behar SM. Eicosanoid pathways regulate adaptive immunity to Mycobacterium tuberculosis. Nat Immunol. 2010;11(8):751-758.

17. Martin CJ, et al. Efferocytosis is an innate antibacterial mechanism. Cell Host Microbe. 2012;12(3):289-300

18. Vandivier RW, Henson PM, Douglas IS. Burying the dead: the impact of failed apoptotic cell removal (efferocytosis) on chronic inflammatory lung disease. Chest. 2006;129(6):1673-1682.

19. Li W. Eat-me signals: keys to molecular phagocyte biology and "appetite" control. JCell Physiol. 2012;227(4):1291-1297.

20. Paidassi H, Tacnet-Delorme P, Arlaud GJ, Frachet P. How phagocytes track down and respond to apoptotic cells. Crit Rev Immunol. 2009;29(2):111-130.
21. Albert ML, et al. Immature dendritic cells phagocytose apoptotic cells via $\alpha v \beta 5$ and CD36, and cross-present antigens to cytotoxic T lymphocytes. J Exp Med.1998;188(7):1359-1368.

22. Nakayama M, et al. Tim-3 mediates phagocytosis of apoptotic cells and cross-presentation. Blood. 2009;113(16):3821-3830.

23. Schulz O, Pennington DJ, Hodivala-Dilke K, Febbraio M, Reis e Sousa C. CD36 or $\alpha v \beta 3$ and $\alpha v \beta 5$ integrins are not essential for MHC class I cross-presentation of cell-associated antigen by $\mathrm{CD} 8 \alpha^{+}$murine dendritic cells. J Immunol. 2002;168(12):6057-6065.

24. Morand EF, Hutchinson P, Hargreaves A, Goulding NJ, Boyce NW, Holdsworth SR. Detection of intracellular lipocortin 1 in human leukocyte subsets. Clin Immunol Immunopathol. 1995;76(2):195-202.

25. Perretti M, D’Acquisto F. Annexin A1 and glucocorticoids as effectors of the resolution of inflammation. Nat Rev Immunol. 2009;9(1):62-70.

26. Perretti M, Dalli J. Exploiting the Annexin A1 pathway for the development of novel antiinflammatory therapeutics. Br J Pharmacol. 2009;158(4):936-946.

27. Arur S, et al. Annexin I is an endogenous ligand that mediates apoptotic cell engulfment. Dev Cell. 2003;4(4):587-598.

28. D’Acquisto F, et al. Annexin-1 modulates T-cell activation and differentiation. Blood. 2007;109(3):1095-1102.

29. D’Acquisto F, Paschalidis N, Sampaio ALF, Merghani A, Flower RJ, Perretti M. Impaired T cell activation and increased Th2 lineage commitment in Annexin-1-deficient T cells. Eur J Immunol. 2007;37(11):3131-3142.

30. D’Acquisto F, Piras G, Rattazzi L. Pro-inflammatory and pathogenic properties of Annexin-A1: the whole is greater than the sum of its parts. Biochem Pharmacol. 2013;85(9):1213-1218.

31. Gan H, Lee J, Ren F, Chen M, Kornfeld H, Remold HG. Mycobacterium tuberculosis blocks crosslinking of annexin-1 and apoptotic envelope formation on infected macrophages to maintain virulence. Nat Immunol. 2008;9(10):1189-1197.

32. Caruso AM, Serbina N, Klein E, Triebold K, Bloom BR, Flynn JL. Mice deficient in CD4 T cells have only transiently diminished levels of IFN- $\gamma$, yet succumb to tuberculosis. J Immunol. 1999;162(9):5407-5416.

33. Winau F, Kaufmann SHE, Schaible UE. Apoptosis paves the detour path for CD8 T cell activation against intracellular bacteria. Cell Microbiol. 2004;6(7):599-607.

34. Iyoda $\mathrm{T}$, et al. The $\mathrm{CD} 8^{+}$dendritic cell subset selectively endocytoses dying cells in culture and in vivo. J Exp Med. 2002;195(10):1289-1302.

35. Viaud S, et al. Dendritic cell-derived exosomes for cancer immunotherapy: what's next? Cancer Res. 2010;70(4):1281-1285.

36. Huggins A, Paschalidis N, Flower RJ, Perretti M, D’Acquisto F. Annexin-1-deficient dendritic cells acquire a mature phenotype during differentiation. FASEB J. 2009;23(4):985-996.

37. Hannon R, et al. Aberrant inflammation and resistance to glucocorticoids in annexin $1^{-1}$ mouse. FASEB J. 2003;17(2):253-255.

38. Chen M, et al. Lipid mediators in innate immu- nity against tuberculosis: opposing roles of PGE2 and LXA4 in the induction of macrophage death. JExp Med. 2008;205(12):2791-2801.

39. Hildner K, et al. Batf3 deficiency reveals a critical role for $\mathrm{CD} 8 \alpha^{+}$dendritic cells in cytotoxic $\mathrm{T}$ cell immunity. Science. 2008;322(5904):1097-1100.

40. Barreiro LB, Tailleux L, Pai AA, Gicquel B, Marioni JC, Gilad Y. Deciphering the genetic architecture of variation in the immune response to Mycobacterium tuberculosis infection. Proc Natl Acad Sci U S A. 2012;109(4):1204-1209.

41. Pilli M, et al. TBK-1 promotes autophagy-mediated antimicrobial defense by controlling autophagosome maturation. Immunity. 2012;37(2):223-234.

42. Blackwell GJ, Carnuccio R, Di Rosa M, Flower RJ, Parente L, Persico P. Macrocortin: a polypeptide causing the anti-phospholipase effect of glucocorticoids. Nature. 1980;287(5778):147-149.

43. Flower RJ. Eleventh Gaddum memorial lecture. Lipocortin and the mechanism of action of the glucocorticoids. Br J Pharmacol. 1988;94(4):987-1015.

44. Parente L, Solito E. Annexin 1: more than an anti-phospholipase protein. Inflamm Res. 2004;53(4):125-132.

45. Da Cunha EE, Oliani SM, Damazo AS. Effect of annexin-A1 peptide treatment during lung inflammation induced by lipopolysaccharide. Pulm Pharmacol Ther. 2012;25(4):303-311.

46. Getting SJ, Flower RJ, Perretti M. Inhibition of neutrophil and monocyte recruitment by endogenous and exogenous lipocortin 1. Br J Pharmacol.1997;120(6):1075-1082.

47. Poon IKH, Lucas CD, Rossi AG, Ravichandran KS. Apoptotic cell clearance: basic biology and therapeutic potential. Nat Rev Immunol. 2014;14(3):166-180.

48. Weyd H, et al. Annexin A1 on the surface of early apoptotic cells suppresses $\mathrm{CD} 8^{+} \mathrm{T}$ cell immunity. PLoS One. 2013;8(4):e62449.

49. Green DR, Ferguson T, Zitvogel L, Kroemer G. Immunogenic and tolerogenic cell death. Nat Rev Immunol. 2009;9(5):353-363.

50. Desch AN, et al. $\mathrm{CD}_{103}{ }^{+}$pulmonary dendritic cells preferentially acquire and present apoptotic cell-associated antigen. J Exp Med. 2011;208(9):1789-1797.

51. Schnorrer $\mathrm{P}$, et al. The dominant role of $\mathrm{CD} 8^{+}$ dendritic cells in cross-presentation is not dictated by antigen capture. Proc Natl Acad Sci U S A. 2006;103(28):10729-10734.

52. Edelson $\mathrm{BT}$, et al. Peripheral $\mathrm{CD}_{103^{+}}$dendritic cells form a unified subset developmentally related to $\mathrm{CD} 8 \alpha^{+}$conventional dendritic cells. JExp Med. 2010;207(4):823-836.

53. Gene Skyline. annexin A1 probe 10466606. Immunological Genome Project Web site. http:// www.immgen.org/databrowser/index.html. Accessed November 19, 2014.

54. Kang J-H, Li M, Chen X, Yin X-M. Proteomics analysis of starved cells revealed Annexin A1 as an important regulator of autophagic degradation. Biochem Biophys Res Commun. 2011;407(3):581-586.

55. Gutierrez MG, Master SS, Singh SB, Taylor GA, Colombo MI, Deretic V. Autophagy is a defense mechanism inhibiting BCG and Mycobacterium tuberculosis survival in infected macrophages. 
Cell. 2004;119(6):753-766.

56. Ponpuak M, et al. Delivery of cytosolic components by autophagic adaptor protein $\mathrm{p} 62$ endows autophagosomes with unique antimicrobial properties. Immunity. 2010;32(3):329-341.

57. Jagannath C, Lindsey DR, Dhandayuthapani S, Xu Y, Hunter RL Jr, Eissa NT. Autophagy enhances the efficacy of BCG vaccine by increasing peptide presentation in mouse dendritic cells. Nat Med. 2009;15(3):267-276.

58. Patterson NL, Mintern JD. Intersection of autophagy with pathways of antigen presentation. Protein Cell. 2012;3(12):911-920.

59. Li Y, Wang L-X, Yang G, Hao F, Urba WJ, Hu $\mathrm{H}-\mathrm{M}$. Efficient cross-presentation depends on autophagy in tumor cells. Cancer Res. 2008;68(17):6889-6895.

60. Li W, et al. Autophagy genes function sequentially to promote apoptotic cell corpse degradation in the engulfing cell. J Cell Biol. 2012;197(1):27-35.
61. Diakonova M, Gerke V, Ernst J, Liautard JP, van der Vusse G, Griffiths G. Localization of five annexins in J774 macrophages and on isolated phagosomes. JCell Sci. 1997;110(pt 10):1199-1213.

62. Seemann J, Weber K, Osborn M, Parton RG, Gerke V. The association of annexin I with early endosomes is regulated by $\mathrm{Ca}^{2+}$ and requires an intact N-terminal domain. Mol Biol Cell. 1996;7(9):1359-1374.

63. Bitto E, Li M, Tikhonov AM, Schlossman ML, Cho W. Mechanism of annexin I-mediated membrane aggregation. Biochemistry. 2000;39(44):13469-13477.

64. De la Fuente M, Parra AV. Vesicle aggregation by annexin I: role of a secondary membrane binding site. Biochemistry. 1995;34(33):10393-10399.

65. Hu NJ, Bradshaw J, Lauter H, Buckingham J, Solito E, Hofmann A. Membrane-induced folding and structure of membrane-bound annexin A1 N-terminal peptides: implications for annexin- induced membrane aggregation. Biophys J. 2008;94(5):1773-1781.

66. World Health Organization. Global Tuberculosis Report 2013. Geneva, Switzerland: World Health Organization; 2013.

67. Tzelepis F, et al. Intrinsic role of FoxO3a in the development of CD8 ${ }^{+} \mathrm{T}$ cell memory. J Immunol. 2013;190(3):1066-1075.

68. Qiu CH, Miyake Y, Kaise H, Kitamura H, Ohara O, Tanaka M. Novel subset of CD8\{alpha\}+ dendritic cells localized in the marginal zone is responsible for tolerance to cell-associated antigens. JImmunol. 2009;182(7):4127-4136.

69. Smyth GK. Linear models and empirical bayes methods for assessing differential expression in microarray experiments. Stat Appl Genet Mol Biol. 2004;3:Article3.

70. Storey JD, Tibshirani R. Statistical significance for genomewide studies. Proc Natl Acad Sci U S A. 2003;100(16):9440-9445. 